\title{
KAPSARC Oil Market Outlook (KOMO)
}

Q2, 2020

NkAPSARC

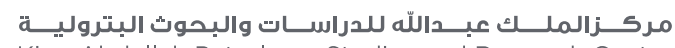
King Abdullah Petroleum Studies and Research Center 


\section{Summary}

The recent declaration by OPEC and its partners (OPEC+), alongside the G20 and some non-G20 countries (OPEC++), to cut oil production should help stabilize the market over the coming quarters. OPEC+ took the lead in finalizing the agreement to cut global production by 9.7 million barrels per day (MMb/d) starting May 1, then $7.7 \mathrm{MMb} / \mathrm{d}$ in the second half of 2020. This should, in turn, help the oil industry as prices recover gradually. Nevertheless, a prolonged period of low oil prices accompanied by low investment in oil is expected to have a strong negative impact on producers in 2021. The current cuts do not fully compensate for the declines in demand seen in April or projected for Q2, but they will significantly help to balance the market going forward. Demand in the second quarter of 2020 is expected to decline by around $14.3 \mathrm{MMb} / \mathrm{d}$. Nevertheless, the impact of COVID-19 and its spillover effects worldwide, with countries taking extreme measures to contain the virus, is expected to result in a year-on-year (YoY) decline of around 7.3 MMb/d in 2020. This is by far the largest annual decline ever recorded. When comparing the estimated production cuts agreed this month with the decline in demand, it is safe to assume that the market will begin rebalancing in the coming quarters. That said, a large supply deficit is expected around Q4 2020, but it will take quite some time to balance global inventories.

Due to the current unprecedented situation, this quarter's KOMO has required significant analyst interventions regarding its assumptions. Further revisions will be needed as the oil market responds to the evolution of COVID-19. There are unusually large uncertainties around this outlook, with a wide range of potential pathways for both global demand and supply. 


Demand Supply

\section{Summary continued...}

- Total global oil demand is expected to decline by 7.3 MMb/d in 2020 and rebound in 2021 by $5.6 \mathrm{MMb} / \mathrm{d}$, returning to its 2019 levels in Q1 2022. These declines are due to the measures taken to address COVID-19 and the deepest global recession of the post-war era. The economic recoveries of many OECD countries, as well as those in the Middle East, Africa and Latin America, are expected to plateau, while Asia and Eurasia are expected to lead the rebound in demand in 2021.

- Declines in total global oil supply are expected throughout 2020 and 2021, with OPEC+ members assumed to be complying with their cuts this year. These cuts may be relaxed slightly in 2021 . However, production will continue to be impacted globally due to low prices and production shutdowns. This impact will be more visible in 2021 for many non-OPEC countries.

1. Total global liquids production is expected to decline by $7.3 \mathrm{MMb} / \mathrm{d}$ in 2020 and rebound in 2021 by $1.2 \mathrm{MMb} / \mathrm{d}$.

2. Shale production is expected to decline by $1.56 \mathrm{MMb} / \mathrm{d}$ in 2020 and by 300 thousand barrels per day (Kb/d) in 2021.
- The supply/demand trends suggest that there will be an average global surplus of $500 \mathrm{~Kb} / \mathrm{d}$ in 2020. However, we expect a surplus of $7 \mathrm{MMb} / \mathrm{d}$ for this quarter, suggesting real challenges for stock and inventory allocation as well as for their products, and a deficit of $3.9 \mathrm{MMb} / \mathrm{d}$ in 2021. The current 2021 balances forecast assumes that OPEC+ members will continue with their announced production cuts throughout 2021. However, based on the projected imbalances in 2021 , the estimated deficit suggests that OPEC+ members may ease their cuts in early 2021 in the face of large ongoing inventory withdrawals. This will allow inventories to reach satisfactory levels. As a result, oil balances are expected to tighten significantly by the first quarter of 2021 , although real inventories are expected to hover around their five-year averages.

- Under these assumptions, target inventory levels for the OECD are expected to stagnate at 4,553 MMb in 2020 and increase by $26 \mathrm{MMb}$ in 2021. Real inventory levels are expected to reach $4,810 \mathrm{MMb}$ in 2020 and decline by $491 \mathrm{MMb}$ in 2021, remaining below target levels and creating a conducive environment for prices to rise gradually.

\begin{tabular}{c|c|c|c|c|c} 
& 2019 & 2020 & $\Delta$ & 2021 & $\Delta$ \\
\hline Demand & 99.9 & 92.7 & -7.26 & 98.3 & 5.61 \\
\hline Supply & 100.5 & 93.2 & -7.33 & 94.4 & 1.20 \\
\hline$\Delta$ & 0.589 & 0.521 & & -3.9 &
\end{tabular}

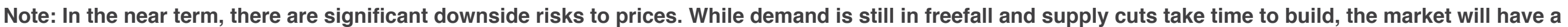

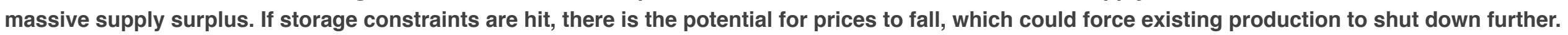




\section{Summary (prices)}

The confidence interval is derived from options market prices and the futures curve, which represent the views of a wide array of market participants, such as speculators, producers, refiners, airlines, among others.

While the market currently expects a steep contango, we also estimate that prices will gradually increase and be supported in the second half of 2020. By far the biggest variable is demand. For both 2020 and 2021, the depth and duration of the economic downturn, and the policy measures to manage the spread, will dwarf the impact of the supply cuts on oil prices.
Brent crude oil price and $50 \%, 68 \%$, and $95 \%$ confidence intervals (US $\$ / b)$

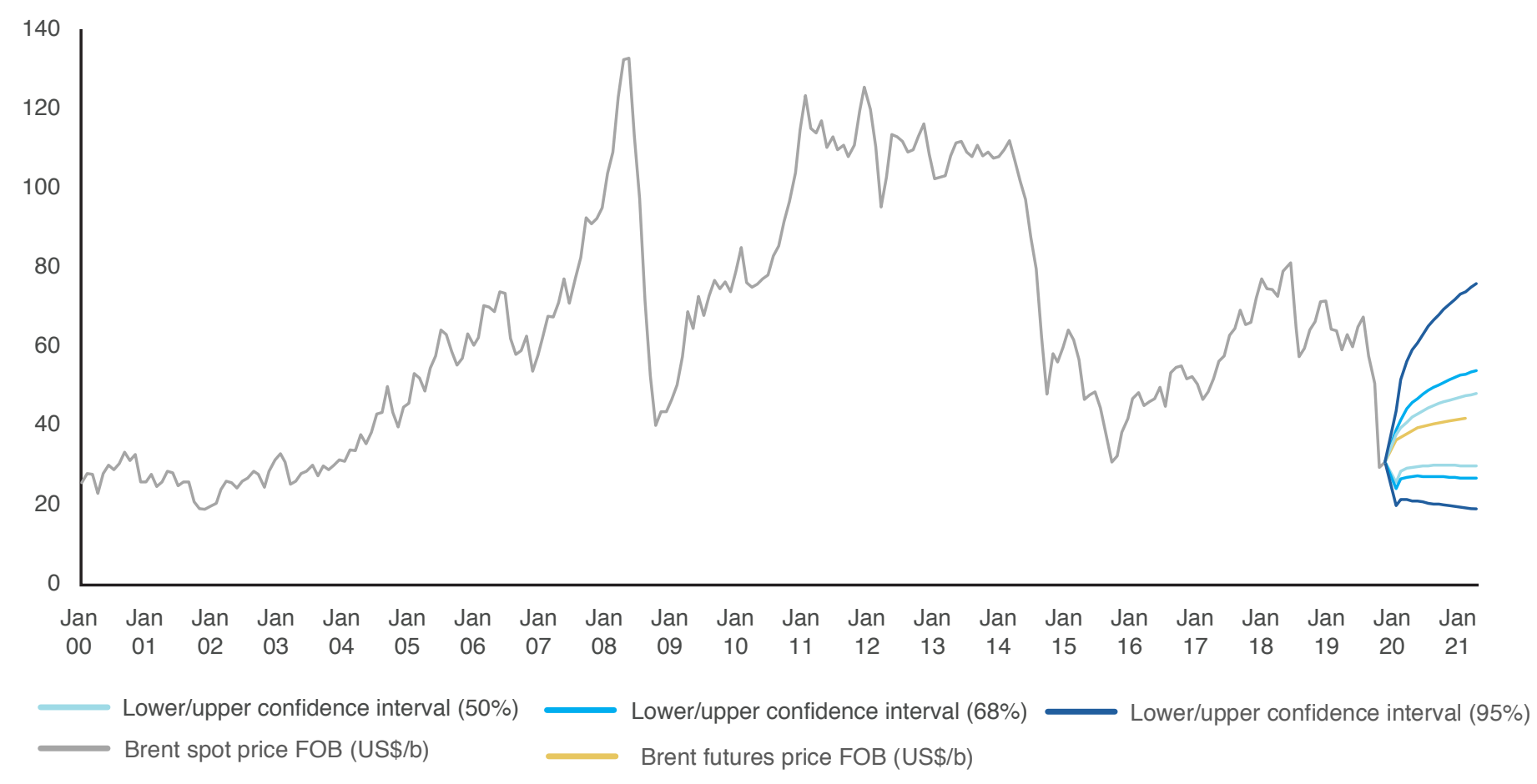

Source: KAPSARC calculations based on NYMEX data, CME Group, FINCAD, April 2020.

\begin{tabular}{|c|c|c|c|c|c|c|c|c|}
\hline US\$/b & Q2 2020 & Q3 2020 & Q4 2020 & Q1 2021 & Q2 2021 & Q3 2021 & Q4 2021 & Q1 2022 \\
\hline Futures & $\$ 28$ & $\$ 36$ & 39 & $\$ 40$ & $\$ 41$ & $\$ 42$ & $\$ 42$ & $\$ 43$ \\
\hline $50 \% \mathrm{Cl}$ & $\$ 25-\$ 30$ & $\$ 29-\$ 40$ & $\$ 30-\$ 44$ & $\$ 30-\$ 45$ & $\$ 30-\$ 47$ & $\$ 30-\$ 48$ & $\$ 31-\$ 49$ & $\$ 31-\$ 51$ \\
\hline $68 \% \mathrm{Cl}$ & $\$ 25-\$ 32$ & $\$ 27-\$ 43$ & $\$ 27-\$ 48$ & $\$ 27-\$ 50$ & $\$ 26-\$ 52$ & $\$ 26-\$ 53$ & $\$ 26-\$ 55$ & $\$ 25-\$ 60$ \\
\hline $95 \% \mathrm{Cl}$ & $\$ 22-\$ 35$ & $\$ 21-\$ 56$ & $\$ 21-\$ 63$ & $\$ 20-\$ 68$ & $\$ 19-\$ 72$ & $\$ 19-\$ 75$ & $\$ 18-\$ 80$ & $\$ 17-\$ 88$ \\
\hline
\end{tabular}

Note: $\mathrm{Cl}=$ confidence interval 


\section{Key issues for the oil market in 2020 and 2021}

In the history of oil markets, the world has never witnessed simultaneous supply and demand shocks to the degree we are now seeing. The recent OPEC++ meeting should eventually help stabilize the market. Amid the COVID-19 pandemic, an estimated three billion people have been put under quarantine. Oil demand has fallen due to the general reduction in global economic activity and specific measures aimed at reducing transportation and mobility (including both air and ground transport). The duration of global measures to "flatten the curve" of the virus's spread suggests a recession that is expected to go beyond 2020. Some may argue that most assets have not been compromised and that there should be a strong rebound after the crisis passes, but it is also prudent to highlight the number of jobs lost. Unemployment levels in some countries have very likely surpassed those of the 2007-2008 financial crisis, which took over two years to recuperate. On April 9, an International Monetary Fund (IMF) spokesperson announced that the world is witnessing "the worst economic fall-out since the great depression." However, the most difficult part of this period is that the depth and duration of this situation remain unclear.

- The IMF forecasts that global gross domestic product (GDP) for 2020 will decline by $3 \%$, compared with growth of $2.9 \%$ in 2019 . It also forecasts that a majority of countries (over 170) will witness negative per capita income growth in 2020 .
- Until stimulus packages are distributed, the banking system will face pressure. Couple this with the prolonged negative, or low, short-term interest rates in many OECD countries, there is the threat of deflation and rising unemployment.

- Geopolitical tensions may ease during this period as many countries are facing internal challenges. Nevertheless, disagreements between the United States (U.S) and China, Pakistan and India, alongside weakening European Union (EU) solidarity, Latin America's sluggish growth and Turkey's provocations remain. Many other issues may also emerge due to the dire global economic situation.

Further progress on resolving the U.S.-China trade war, alongside other international resolutions on trade, geopolitics, intellectual property, and increasing financial market sentiment and investor confidence with tailored stimulus packages, could help promote crude oil demand and increase crude oil prices throughout the forecast period. Ultimately, finding a viable vaccine and/or citizens returning to work early remains the most important factor behind a demand recovery. Indeed, the focus on the recovery after the COVID-19 pandemic should be on all countries, including many OECD countries, as it is estimated that their recovery may be slower than that of many developing countries.
KOMO's supply/demand forecast is an average for each period and does not take into account short-term volatility. Actual changes to supply and demand will, of course, remain volatile in light of the responses to and the duration of the COVID-19 pandemic. Other challenges may include unexpected oil supply cuts, OPEC+ compliance, and upheavals in developing countries, among others.

On the supply side, U.S. shale production has already started to respond to lower prices, and the shale industry is facing a substantial decline in drilling and an increase in bankruptcies. Although shale producers are likely to reduce costs due to lower oil prices, the U.S. capex indicates that only $30 \%-40 \%$ of existing shale companies will be able to withstand a sustained low-price environment. Many observers feel that the industry's capacity to realize further production cost reductions and improved productivity is limited. We do not expect a rebound in production until late 2022. While the announced OPEC++ cuts of April 12 are probably insufficient to bounce prices back to their January levels, they will provide a lifeline to several shale producers in the U.S., resulting in continued, albeit declining, North American shale production. Although 2020 was expected to witness increased conventional oil output in Brazil, Norway, Argentina and Guyana, among other countries, the current price environment is expected to reduce their production growth. 
Key issues for the oil market in 2020 and 2021 continued...

Moreover, alongside the U.S., countries such as Norway and Brazil are also expected to participate in the global cuts. These cuts can either be considered as part of the OPEC++ pact or perceived as natural declines due to dwindling investment in oil and low prices. Indeed, Petrobras declared a cut of $200 \mathrm{~Kb} / \mathrm{d}$ before the OPEC meeting. Norway has historically cut its production on some occasions due to low prices, the U.S will shed its most inefficient producers due to their deteriorating economics, while the Texas Railroad Commission is looking into a possible cut of $20 \%$ for their producers. However, what is most surprising is not what is expected to happen in 2020 , as this has already been decided to a certain extent, but rather what we presume for 2021. During 2021, the majority of producing countries will see declines in their production due to the low-price environment, as investment reductions implemented now begin to impact future supply. Falling
non-OPEC supply, combined with recovering demand, may create space for OPEC+ members to ease their announced production cuts sooner than currently planned.

Despite upward price risk, currently strong inventory levels, which will persist throughout 2020, should mitigate any short-term supply shocks and result in gradual price movements with less volatility. In the very near term, prices could see additional downward pressure if global inventory capacity is reached, which would force prices to fall and existing production to halt.

Expected balances suggest that OPEC++ may consider adjusting their cuts by Q4 2020. Nonetheless, our current balance is built around an assumption that the announced cuts will hold and that the pandemic will gradually wind down. Both are subject to the upcoming June meetings of OPEC++.
It seems as if the maritime industry is impacted to a lesser extent by the COVID-19 disruption than other industries by the global need to maintain robust supply chains. Some countries, including the United Kingdom (U.K.) and those in Asia, have suspended checks on ships for compliant fuels and safety measures. As a result, high sulfur fuel oil (HSFO) is expected to be consumed at a higher rate than expected, especially since the usage of scrubbers has proved to be effective. Onshore, demand for diesel (the fuel for supply chains) has similarly been less impacted compared with gasoline and jet fuel. These distortions in relative refined product demand will have implications for refining margins. 


\section{Factors influencing price}

- Finding a solution (vaccine) to the COVID-19 pandemic

- Increasing fiscal stimulus and more liquidity for emerging markets

- Faster OECD recovery

- Stronger non-OECD rebound/growth

Future catalysts for price strength

- OPEC++ level of compliance

- Recovery from COVID-19 and loosening measures

- Recession recovery and restoring market confidence

- Multilateral and national actions and policies

- Waning investment tightening supply - shale and offshore shutdowns in the North Sea and the Gulf of Mexico

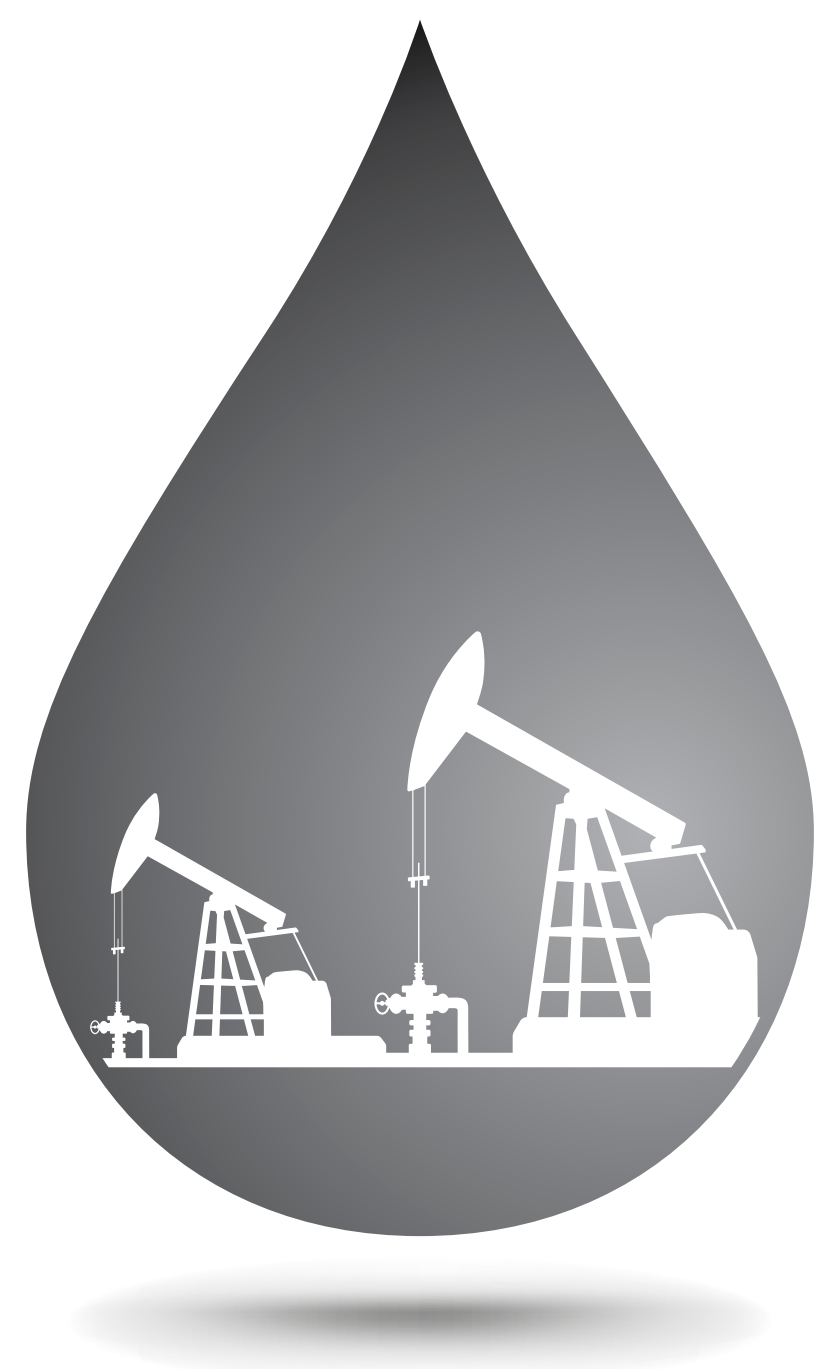

- Impact of the global recession*

- Prolonged quarantine measures for COVID-19

- Global inventory stockpile overhang

- Prolonged financial tightening and unsustainable debts

- Stronger non-OPEC supply (shale and conventional)

- Declining costs of stranded oil assets

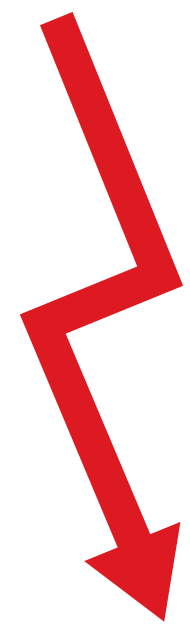

* The IMF has stated that this is the worst economic fallout since the Great Depression. 


\section{Assumptions}

A demand forecast is usually dependent on historical facts. News from China indicates the virus was contained within four months. We therefore assume an effective way of addressing the situation would be to allow each country a grace period of between four to seven months since the start of their respective outbreaks. The difference in this timing will depend on how effective governments are in controlling their respective outbreaks and placing strict measures on their economies. With these assumptions in place, we observe that most countries began their 'real' outbreaks in March, except for North and South America (representing 32\% of global oil demand) and Africa (representing $4 \%$ of global oil demand).

It is also prudent to mention that demand will not reach a complete halt in all the impacted countries. Gasoline and, to a lesser degree, diesel consumption for transportation will decline, as will jet fuels, but the maritime industry is expected to be less affected, as goods will continue to be distributed thanks to robust supply chains. Many developing countries under quarantine will still require higher rates of liquefied petroleum gas (LPG) for cooking.

The outbreak of the virus is also expected to impact countries differently in two ways:

a) Depending on economic resilience: countries with more resilient economies or more aggressive containment policies are expected to maintain longer periods of quarantine. However, countries with more citizens living paycheck to paycheck will be obliged to shorten their quarantine periods and accept higher rates of infection.

b) Depending on geographical location: COVID-19 arrived at each country at a different time. We assume that by the time the spread takes hold strongly in Latin America, some Southeast Asian countries will likely be at the tail-end of their outbreaks.

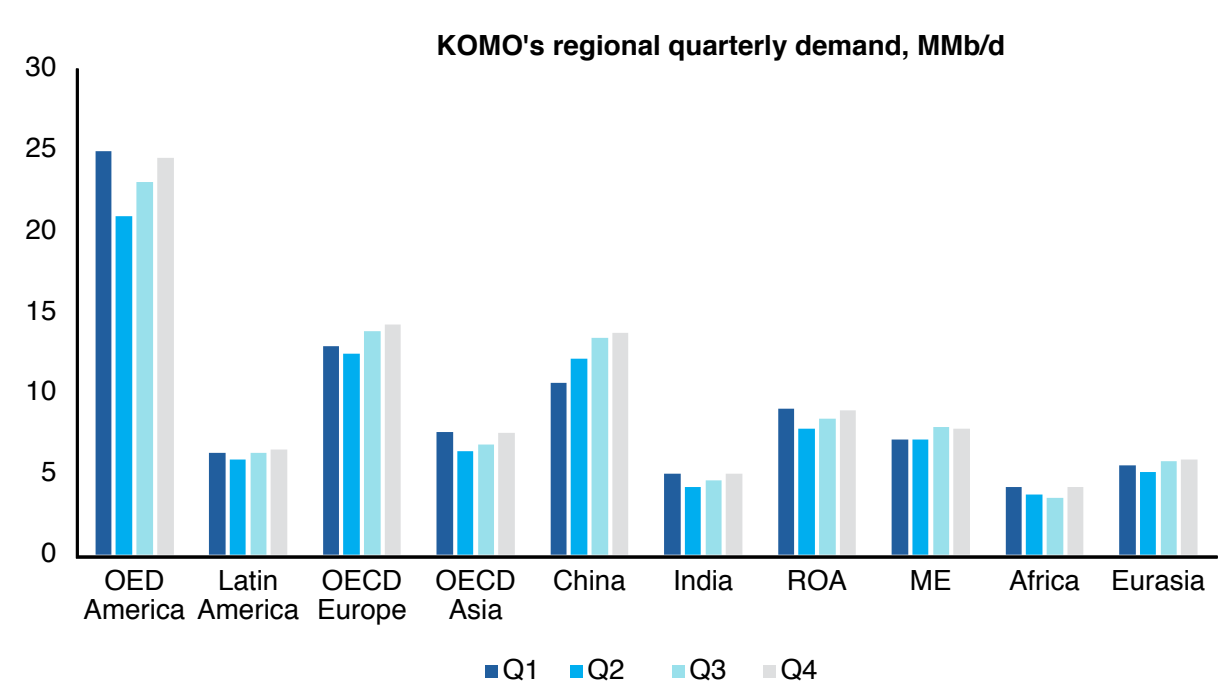

KOMO's monthly demand change assumptions, 2020 (MMb/d)

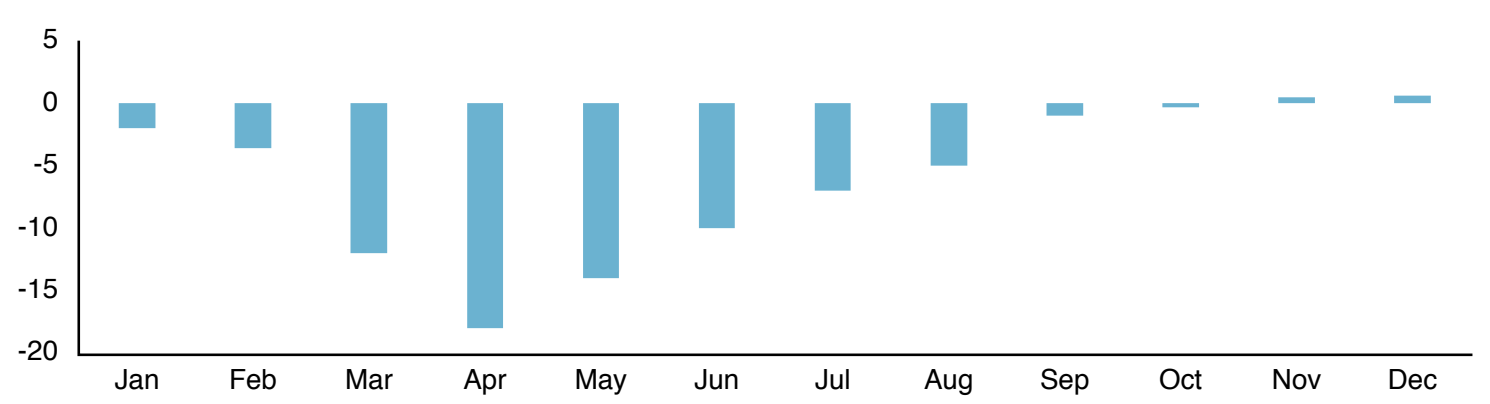

As such, and based on the following assumptions, we would expect a yearly decline in global oil demand of between $5 \mathrm{MMb} / \mathrm{d}$ to $10 \mathrm{MMb} / \mathrm{d}$. In this update, we assume that total global demand is likely to decline by around 7.3 MMb/d in 2020. However, this number could be revised depending on measures taken in the second quarter and beyond to address the COVID-19 outbreak, its duration, and the depth of the global recession. 


\section{Demand forecast}

Global oil demand is estimated to decline by $7.26 \mathrm{MMb} / \mathrm{d}$ in 2020 and rebound by 5.61 $\mathrm{MMb} / \mathrm{d}$ in 2021. The expected 2020 decline compares with an expected increase of $1.23 \mathrm{MMb} / \mathrm{d}$ in our previous edition before the impact of COVID-19 became apparent. The largest decline in 2020 is expected to be during Q2, with an estimated decline of $14.3 \mathrm{MMb} / \mathrm{d}$ due to the quarantine measures taken by the global community. On a year-on-year (YoY) basis, Asia is expected to witness the strongest decline of 2.4 $\mathrm{MMb} / \mathrm{d}$, followed by OECD Americas at 2.3 MMb/d, then OECD Europe at 1.16 MMb/d.

Demand from OECD members is expected to decline by $4 \mathrm{MMb} / \mathrm{d}$ and represent $47 \%$ of total global oil demand, whereas the demand from non-OECD members is expected to decline by $3.26 \mathrm{MMb} / \mathrm{d}$ and represent $53 \%$ of total global demand. OECD nations will have a proportionally larger impact on demand because much of their consumption is more discretionary than that of non-OECD countries. GDP for 2021 is expected to bounce back and prices are expected to gradually rise at the end of 2020 or early 2021 , though at a slower pace, which we expect will encourage higher demand. Thus, we expect demand growth in OECD countries in 2021 to slow to $2.01 \mathrm{MMb} / \mathrm{d}$, and $3.61 \mathrm{MMb} / \mathrm{d}$ in non-OECD countries. There will be a stronger rebound from developing countries and emerging markets than from OECD countries.

In 2019, global demand grew by $940 \mathrm{~Kb} / \mathrm{d}$, with $1.04 \mathrm{MMb} / \mathrm{d}$ coming from non-OECD countries, and demand from OECD countries declining by $100 \mathrm{~Kb} / \mathrm{d}$.

In 2020, all OECD countries are expected to see oil demand declines. Demand from OECD Americas is expected to decline by $2.3 \mathrm{MMb} / \mathrm{d}$, OECD Europe is expected to decline by $1.16 \mathrm{MMb} / \mathrm{d}$ and OECD Asia-Oceania is expected to decline by $560 \mathrm{~Kb} / \mathrm{d}$. However, in 2021, OECD Americas is expected to rebound and grow by $1.2 \mathrm{MMb} / \mathrm{d}$, with the U.S. taking the lead at $1.1 \mathrm{MMb} / \mathrm{d}$. OECD Europe is expected to rebound by $280 \mathrm{~Kb} / \mathrm{d}$ and OECD Asia-Oceania by $485 \mathrm{~Kb} / \mathrm{d}$. Hence, we expect a slower recovery for OECD members, with Asia-Oceania reclaiming its 2019 level the fastest.
Asia is expected to lift the demand of the non-OECD in 2021, with growth of 2.6 MMb/d, compared with its decline of $1.8 \mathrm{MMb} / \mathrm{d}$ in 2020. Latin America and Eurasia are expected to reach, or even slightly exceed, their 2019 levels by the end of 2021. However, the Middle East and Africa are estimated to recover more gradually. This is due to the Middle East being highly energy-income focused. Low prices are less of a driver of demand because there is less money to invest in the tools of consumption (cars, chemical plants, among others.) Whereas Africa will also take a hard hit from this crisis economically since its tools of consumption are highly dependent on foreign investment, which is expected to tighten. Moreover, both regions' IMF GDP forecasts are also reflective of these changes, suggesting a slower rebound in oil demand.

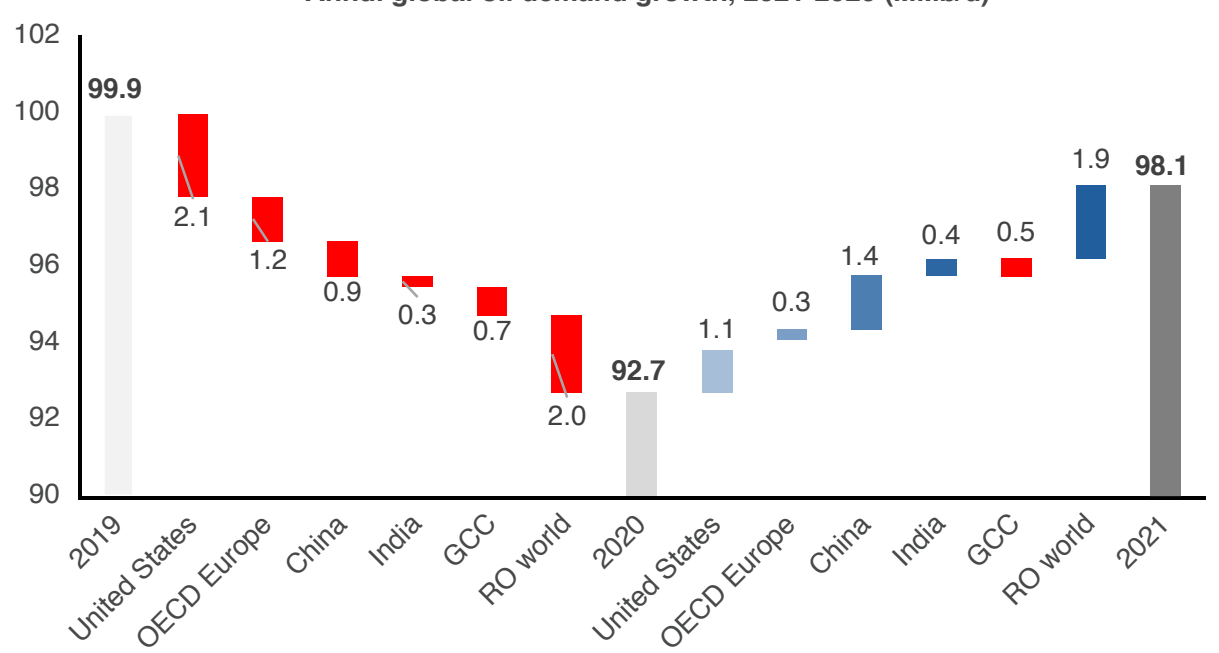

Source: KAPSARC, April 2020 


\section{Demand growth}

\begin{tabular}{l|c|c|c|c|c}
\multicolumn{1}{c|}{2019} & Q1 & Q2 & Q3 & Q4 & 2019 \\
\hline OECD & 48.2 & 47.2 & 48.1 & 48.6 & 48 \\
\hline Non-OECD & 51 & 52.1 & 52.4 & 52.2 & 51.9 \\
\hline Global demand & 99.1 & 99.4 & 100.5 & 100.8 & 99.9
\end{tabular}

Non-OECD is expected to retain its $53 \%$ share of global oil demand in 2020 and 2021 . It will also carry $45 \%$ of demand declines in 2020 and represent $64 \%$ of oil demand growth in 2021.

Regionally, the Americas and Asia will face the largest fluctuation in oil demand growth between 2020 and 2021 due to the large volumes they consume. They will be followed by OECD Europe and the Middle East.

\begin{tabular}{l|c|c|c|c|c}
\multicolumn{1}{c|}{2020} & Q1 & Q2 & Q3 & Q4 & 2020 \\
\hline OECD & 45.7 & 40 & 43.9 & 46.5 & 44 \\
\hline Non-OECD & 47.6 & 45.7 & 49.7 & 51.7 & 48.7 \\
\hline Global demand & 93.3 & 85.7 & 93.6 & 98.2 & 92.7
\end{tabular}

\section{Current demand assumptions are susceptible to significant changes, depending on the impact of} COVID-19 and its duration. Further revisions to these assumptions will be needed as we progress through this quarter.

\begin{tabular}{l|c|c|c|c|c}
\multicolumn{1}{c|}{2021} & Q1 & Q2 & Q3 & Q4 & 2021 \\
\hline OECD & 46.1 & 45.2 & 46.1 & 46.7 & 46 \\
\hline Non-OECD & 51.3 & 52.5 & 52.9 & 52.4 & 52.3 \\
\hline Global demand & 97.4 & 97.6 & 99 & 99.1 & 98.3
\end{tabular}

\begin{tabular}{l|c|}
\multicolumn{1}{c|}{2022} & Q1 \\
\hline OECD & 46.7 \\
\hline Non-OECD & 52.8 \\
\hline Global demand & 99.6
\end{tabular}

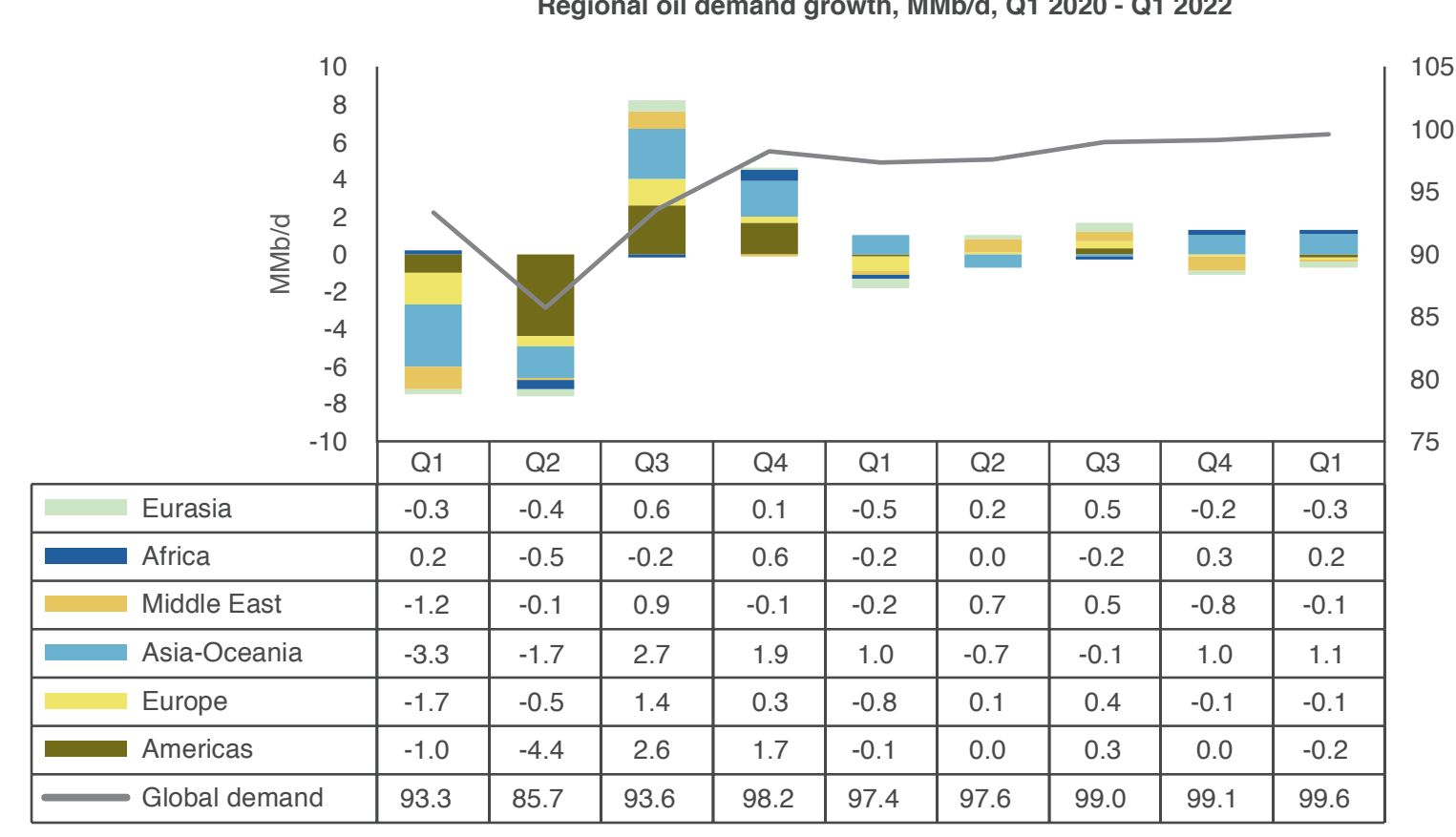

Source: KAPSARC, April 2020. 


\section{United States}

\begin{tabular}{|c|c|c|c|c|c|c|c|c|c|c|c|c|}
\hline $\mathrm{MMb} / \mathrm{d}$ & 2019 & Q1 & Q2 & Q3 & Q4 & 2020 & Q1 & Q2 & Q3 & Q4 & 2021 & Q1 2022 \\
\hline United States & 20.9 & 20.1 & 16.4 & 18.4 & 19.9 & 18.7 & 19.8 & 19.7 & 19.9 & 19.9 & 19.8 & 19.8 \\
\hline
\end{tabular}

\section{Yearly}

U.S. oil demand is expected to decline by $2.14 \mathrm{MMb} / \mathrm{d}$ in 2020, and bounce back by $1.11 \mathrm{MMb} / \mathrm{d}$ in 2021 , remaining far below its 2019 levels. This increment correlates with its expected modest GDP growth for 2021 and the severe unemployment rates expected. These assumptions are also dependent on the country's post-pandemic fiscal recovery policies to address the recession. Transportation fuels are expected to be hit the hardest as they represent more than $60 \%$ of U.S. daily consumption.

In 2020, demand for gasoline in the U.S. is expected to witness the greatest decline $(-3.2 \mathrm{MM} / \mathrm{d})$, followed by jet fuel $(-460 \mathrm{~Kb} / \mathrm{d})$ and then gas/diesel oil, albeit to a limited extent. However, these declines are expected to be compensated by incremental demand for $L P G$ and naphtha during the quarantine phase.

\section{Q2 2020}

Q2 is expected to see a decline in demand of 2.9 $\mathrm{MMb} / \mathrm{d}$ due to the country being on lockdown, with less demand for gasoline $(\approx-3.5 \mathrm{MMb} / \mathrm{d})$ as well as jet fuel $(-360 \mathrm{~Kb} / \mathrm{d})$. This quarter will witness growth in LPG demand of around $100 \mathrm{~Kb} / \mathrm{d}$, whereas all the remaining fuel products are expected to decline.
However, the Trump administration has recently suggested the possibility of loosening lockdown restrictions in May and June, which explains why these estimations are milder than the month-on-month demand reduction in April would suggest.

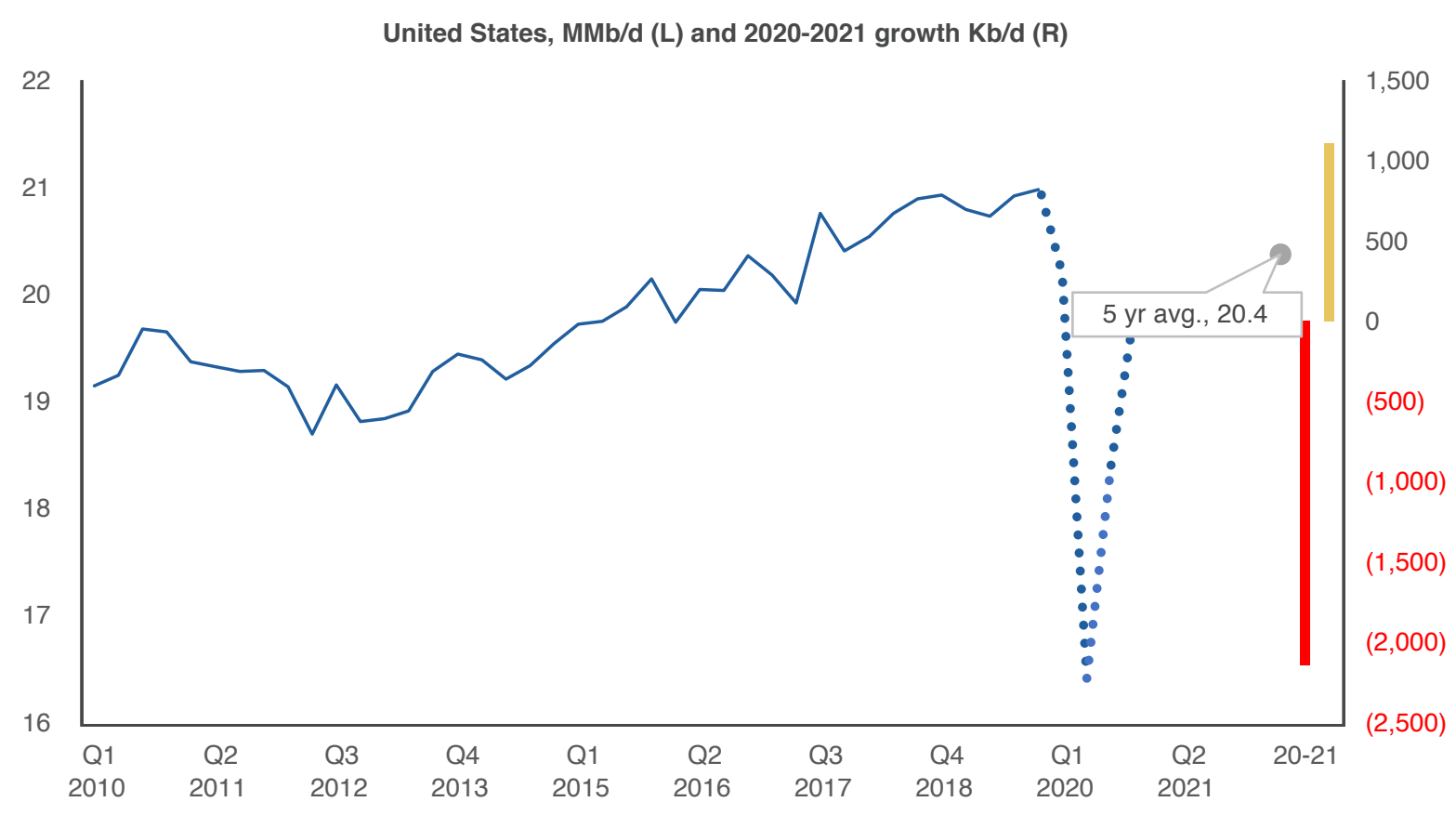

Source: KAPSARC, April 2020. 


\section{OECD Europe}

\begin{tabular}{|c|c|c|c|c|c|c|c|c|c|c|c|c|}
\hline $\mathrm{MMb} / \mathrm{d}$ & 2019 & Q1 & Q2 & Q3 & Q4 & 2020 & Q1 & Q2 & Q3 & Q4 & 2021 & Q1 2022 \\
\hline OECD Europe & 14.5 & 12.9 & 12.4 & 13.8 & 14.2 & 13.3 & 13.4 & 13.4 & 13.9 & 13.8 & 13.6 & 13.6 \\
\hline
\end{tabular}

\section{Yearly}

OECD Europe's oil demand is expected to decline by $1.16 \mathrm{MMb} / \mathrm{d}$ in 2020 and recover by $270 \mathrm{~Kb} / \mathrm{d}$ in 2021 . It is expected that OECD Europe will face the slowest recovery of all the regions due to its continuously prolonged negative short-term interest rates, and the high COVID-19 death tolls in Italy and Spain. Moreover, the EU members' variable responses to the crisis and the closing of their normally open borders may cool investment and economic activity more than expected.

Demand declines are expected to come from gas/ diesel oil (-1.15 MMb/d), followed by motor gasoline $(-600 \mathrm{~Kb} / \mathrm{d})$ and aviation fuels $(-360 \mathrm{~Kb} / \mathrm{d})$. Although we may witness an increase in demand for naphtha and LPG, it will not be enough to recover these losses.

\section{Q2 2020}

Demand in the second quarter is expected to decrease by $500 \mathrm{~Kb} / \mathrm{d}$, following a large decline in Q1, as Europe experienced the impact of COVID-19 earlier than the U.S. This decline will be driven by the expected declines in land transport and aviation. Demand for fuel oil and naptha, however, is expected to rise by $90 \mathrm{~Kb} / \mathrm{d}$ and $55 \mathrm{~Kb} / \mathrm{d}$, respectively.

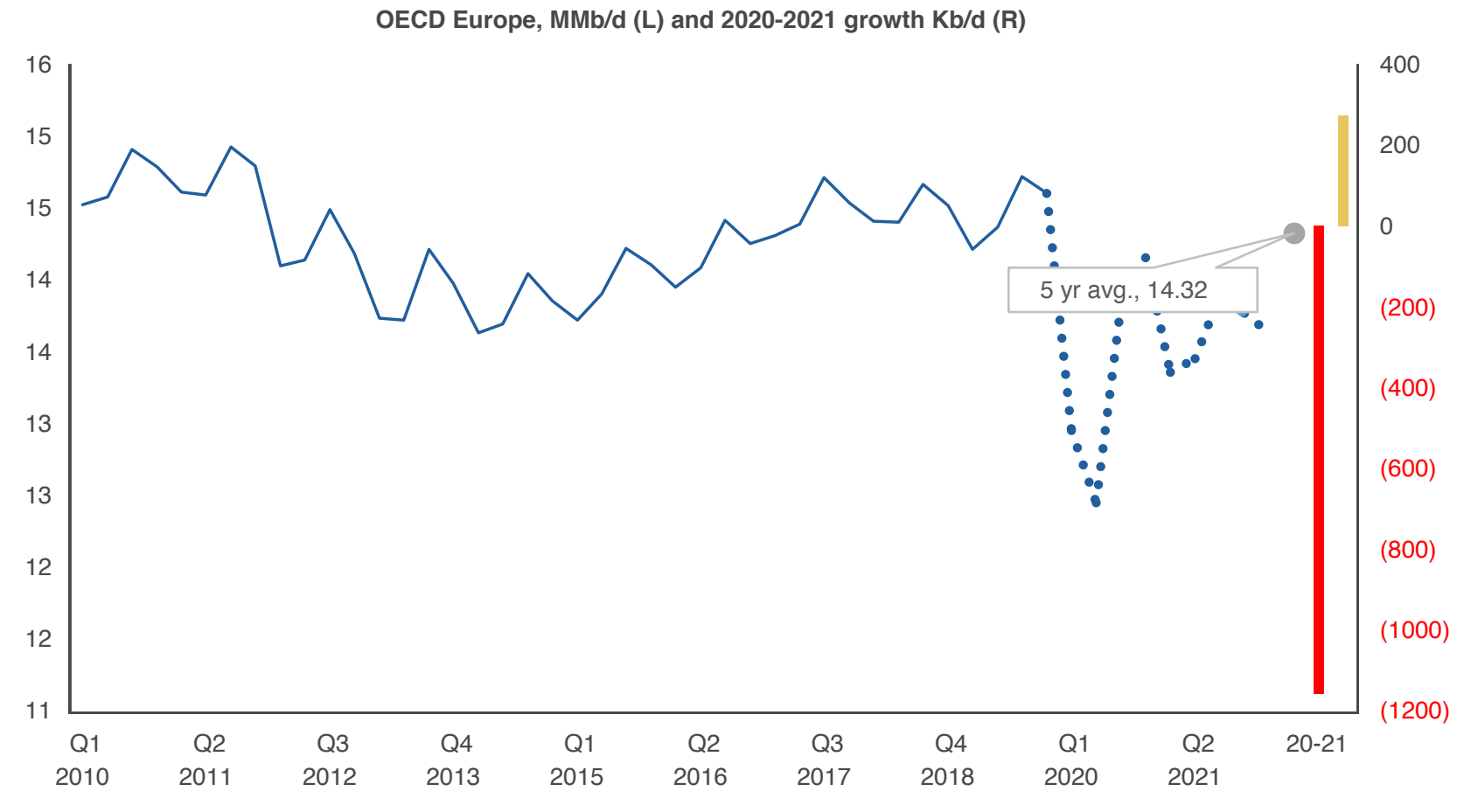




\section{China}

\begin{tabular}{|c|c|c|c|c|c|c|c|c|c|c|c|c|}
\hline $\mathrm{MMb} / \mathrm{d}$ & 2019 & Q1 & Q2 & Q3 & Q4 & 2020 & Q1 & Q2 & Q3 & Q4 & 2021 & Q1 2022 \\
\hline China & 13.3 & 10.6 & 12.1 & 13.4 & 13.7 & 12.4 & 13.7 & 14 & 13.8 & 13.9 & 13.9 & 14.0 \\
\hline
\end{tabular}

\section{Yearly}

China's oil demand is expected to decline by $920 \mathrm{~Kb} / \mathrm{d}$ in 2020 and pick up again in 2021 by $1.4 \mathrm{MMb} / \mathrm{d}$. Unlike OECD countries, China's 2021 demand is expected to exceed that of 2019. China began planning for a decline in its oil projects growth in 2019 and was focusing on several coal-based projects. However, given that China's COVID-19 outbreak occurred early in 2020 , we would assume that many projects have been delayed. Nevertheless, its recovery has progressed and there have been positive reports of healthy refinery throughput in China. Indeed, Petrochina's Ningxia has hiked crude processing rates to $93 \%$ since April 3 , and many teapot refineries are following suit. The decline in prices, the country's general economic recovery, and, to a lesser extent, the global need for a wide array of products to address the pandemic, will lead to increased demand from China. Moreover, China was scheduled for several small expansions in its downstream sectors, which will contribute to a stronger recovery in Q3 and Q4 of 2020 .

China is expected to witness demand declines for all fuel products in 2020, except for naphtha, which will grow slightly by $160 \mathrm{~Kb} / \mathrm{d}$, and demand for LPG will stagnate. A fall in demand for gasoline is expected to account for almost half of China's decline in demand this year.

\section{Q2 2020}

Total fuel consumption is expected to increase by $1.54 \mathrm{MMb} / \mathrm{d}$ in Q2 2020. It seems as if the worst of China's quarantine measures have already passed, with the country emerging from lockdown.
Indeed, Q1 2020 accounts for most of China's declines. Demand for most of the lighter products is expected to grow in Q2 2002, with LPG rising at $200 \mathrm{~Kb} / \mathrm{d}$, naphtha at $350 \mathrm{~Kb} / \mathrm{d}$ and gasoline at around $470 \mathrm{~Kb} / \mathrm{d}$. Demand for jet fuel, though recovering, remains very modest since most countries have limited air travel.

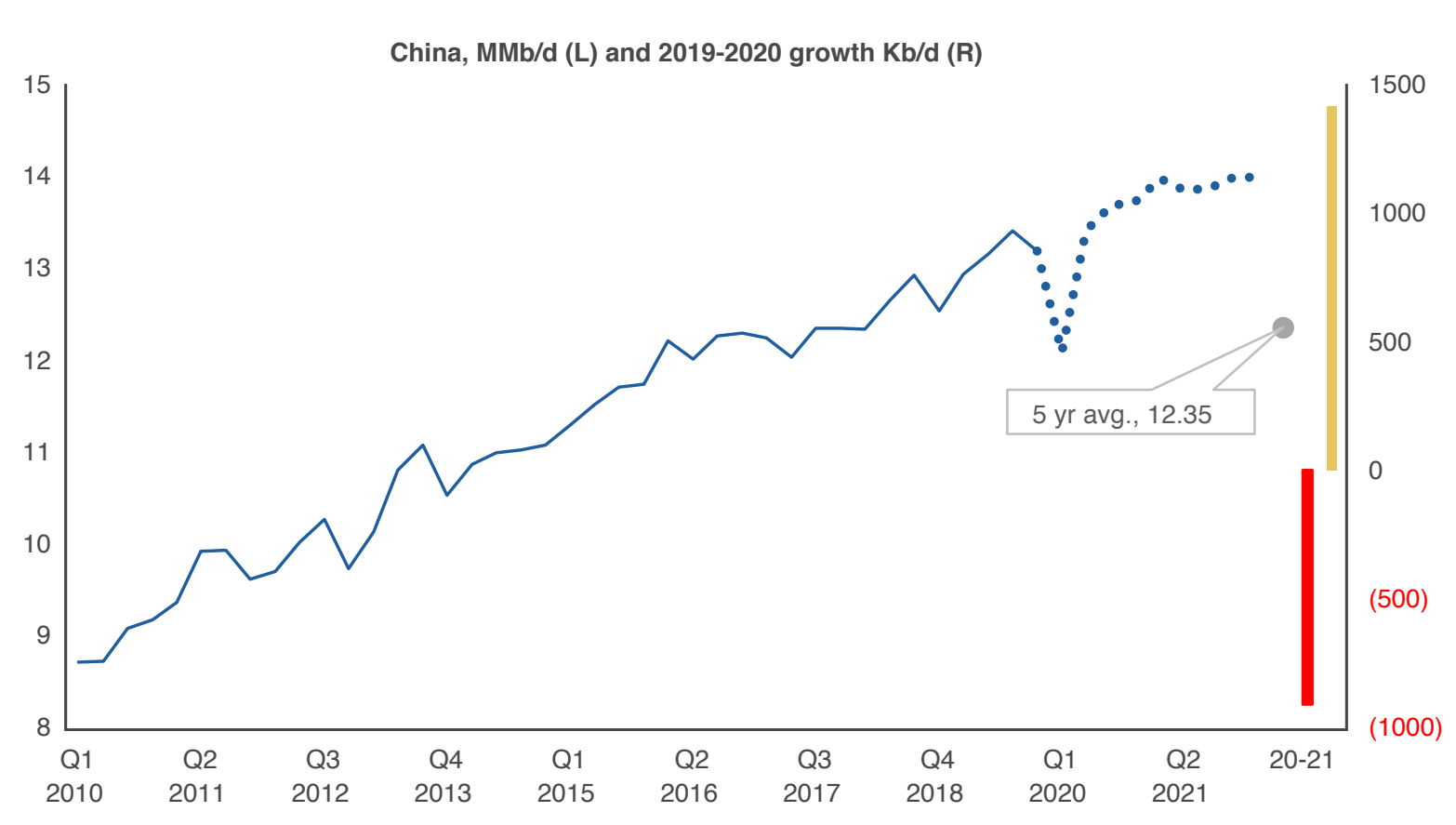

Source: KAPSARC, April 2020. 


\section{India}

\begin{tabular}{|c|c|c|c|c|c|c|c|c|c|c|c|c|}
\hline $\mathrm{MMb} / \mathrm{d}$ & 2019 & Q1 & Q2 & Q3 & Q4 & 2020 & Q1 & Q2 & Q3 & Q4 & 2021 & Q1 2022 \\
\hline India & 5 & 5 & 4.2 & 4.6 & 5 & 4.7 & 5.2 & 5.2 & 4.9 & 5.3 & 5.1 & 5.5 \\
\hline
\end{tabular}

\section{Yearly}

India's oil demand is expected to decline by $270 \mathrm{~Kb} / \mathrm{d}$ in 2020 and rebound strongly by $430 \mathrm{~Kb} / \mathrm{d}$ in 2021 .

India started its severe quarantine measures in March 2020. For some reason, the media anticipated further declines of 5-10 MMb/d in Q2 2020. However, India's total demand is roughly $5 \mathrm{MMb} / \mathrm{d}$, which makes further declines in global liquid demand unlikely. This year India was expected to shift its product demand portfolio from consuming heavy infrastructure products (i.e., asphalt, petcoke, etc.) to transport, but the pandemic has derailed these plans. KOMO's preliminary analysis indicates that products used in infrastructure and LPG demand will stagnate this year. Meanwhile, demand for transportation fuels and naphtha is expected to decline strongly.

India's infrastructure projects for 2020 were geared toward gas distribution, in line with the government's plan to reduce crude oil imports by $10 \%$ in the near future and to increase the share of electric vehicles (EVs) on the roads. However, India, like the rest of the world, is currently facing prolonged quarantine periods. As a result, we assume delays in these initiatives. India may also witness an increase in LPG demand of around $150 \mathrm{~Kb} / \mathrm{d}$. However, the strongest decline in demand will be for LNG and supply chain fuels, with an estimated total liquids demand decline of $230 \mathrm{~Kb} / \mathrm{d}$.

\section{Q2 2020}

India's demand declines this quarter on all products will total $720 \mathrm{~Kb} / \mathrm{d}$. The strongest declines are expected in the fuels classified as 'other products' (-200 Kb/d) used

in infrastructure, followed by gas/diesel oil and LPG with both facing declines of $150 \mathrm{~Kb} / \mathrm{d}$ and gasoline $(-114 \mathrm{~Kb} / \mathrm{d})$.

India, MMb/d (L) and 2020-2021 growth Kb/d (R)

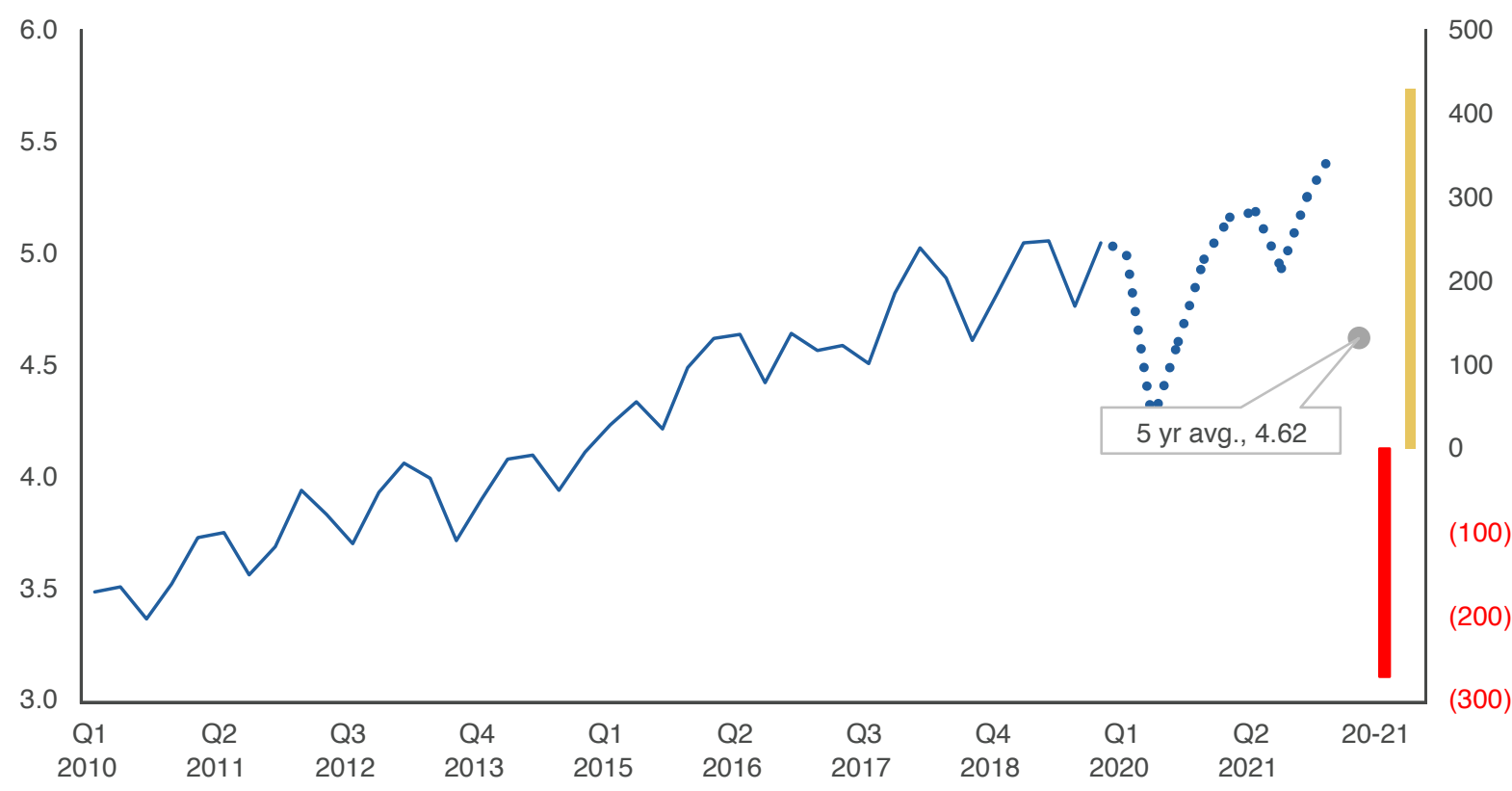

Source: KAPSARC, April 2020 


\section{Saudi Arabia}

\begin{tabular}{c|c|c|c|c|c|c|c|c|c|c|c|c|c|c|c|c|c|c|} 
MMb/d & 2019 & Q1 & Q2 & Q3 & Q4 & 2020 & Q1 & Q2 & Q3 & Q4 & 2021 & Q1 2022 \\
\hline Saudi Arabia & 3.2 & 2.7 & 2.7 & 2.9 & 2.4 & 2.7 & 2.7 & 3.3 & 3.6 & 3.0 & 3.1 & 2.7
\end{tabular}

\section{Yearly}

Saudi Arabia's oil demand is expected to contract by $560 \mathrm{~Kb} / \mathrm{d}$ in 2020 and bounce back by $540 \mathrm{~Kb} / \mathrm{d}$ in 2021.

As we move through the COVID-19 quarantine period, which started in March 2020, we expect declines across all products, with gasoline taking the largest hit (-280 $\mathrm{Kb} / \mathrm{d})$, followed by diesel $(-230 \mathrm{~Kb} / \mathrm{d})$. Other products will account for the remaining decline, except for LPG, which is expected to grow by $30 \mathrm{~Kb} / \mathrm{d}$.

\section{Q2 2020}

Saudi Arabia is expected to increase its oil consumption by $440 \mathrm{~Kb} / \mathrm{d}$ in Q1 2020, despite sharp decreases in gasoline and jet fuel demand. Demand for fuel oil is expected to increase by $320 \mathrm{~Kb} / \mathrm{d}$, followed by LPG $(150 \mathrm{~Kb} / \mathrm{d})$. This increase naturally occurs with the warmer weather, because more liquid fuels are required for electricity and cooling generation.
Saudi Arabia, MMb/d (L) and 2020-2021 growth Kb/d (R)

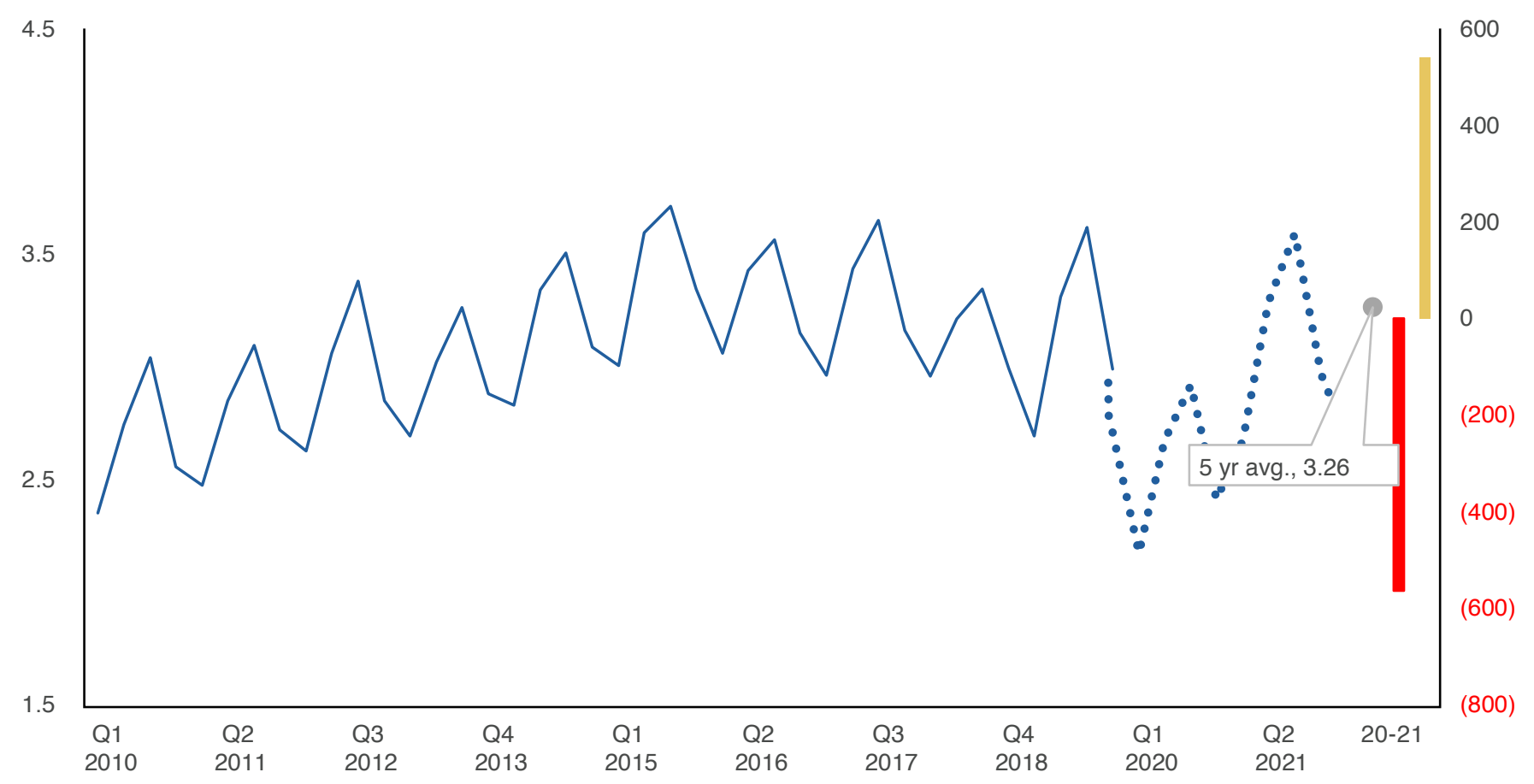




\section{Assumptions}

The current crisis is unprecedented in many ways, and its effects on the oil markets cannot be easily anticipated. The normal economics of supply, demand, and price are inadequate to capture many of the impacts that we have seen. Non-economic factors have become major drivers, so balancing the market is more difficult than ever before, and forecasting when we can return to 'normal' is difficult at best. Under these circumstances, we have adjusted the working of the supply model slightly to account for these unusual times.

The basic technical portion of the model, where assets increase or decrease production based on price, has had more sensitivity added toward the negative end. In normal times, producers with relatively high breakeven prices may be reluctant to shut down, as restarting has significant associated costs. In the current environment, this optimism and delay are removed from the equation due to the depth of the current prices, and the general forward sentiment that a massive rally is highly unlikely within the next few quarters.

This down-shift in optimism sufficiently accounts for some of the changes to normal operations reported in the field. For example, Permian midstream operators are pushing for upstream players to curtail production as inventory fills up. Some Canadian oil sands, normally quite resilient because of the costs of losing heat in a reservoir, are closing. Brazilian and North Sea offshore developments are either closing early or stopping operations temporarily. While the behavior of specific fields may not be exactly as we have modeled, our aggregate predictions appear to hold true.

We assume that OPEC+ will comply fully, but as the market heads toward rebalancing in 2021, strict adherence may become more difficult to maintain as prices increase. However, we expect OPEC+ member production to increase only slightly. Mexico's agreed cut of $100 \mathrm{~Kb} / \mathrm{d}$ is a quarter of its originally proposed cuts and we assume that its cut as part of the agreement will continue at a similar level compared with those of other members throughout the period of the agreement The response to lower prices from the U.S. and other producers outside the OPEC+ group is already captured in our technical analysis.

The "risk table" for producing nations has been deactivated in this update, except for Libya. For all other nations, the current crisis is already constraining production to a level beyond local geopolitical impacts. Libya deserved specific consideration, as its current production has been pushed to very low levels with the blockade of the export terminals. In Libya's case, we expect that 'normal' (economically driven) production levels could gradually return over the course of about a year. We have assumed that the current sanctions on Iran and Venezuela will continue.

Lastly, we have included an unallocated adjustment factor for when we begin to see a recovery in demand in 2021. This was due to the uncertainty associated with which project types might come online sooner than expected. Many of the projects are treating this time period as an extended shutdown or turnaround, so it is difficult to estimate who will come online first. It may be shale if drilling can resume without difficulty, or conventional projects that have been temporarily shut down may be first to supply the additional demand growth. 


\section{Supply forecast}

Global liquids supply is expected to fall by an average of $7.3 \mathrm{MMb} / \mathrm{d}$ in 2020 to reach $93.2 \mathrm{MMb} / \mathrm{d}$, as OPEC+ cuts attempt to offset the significant fall in demand and U.S. shale feels the impact of a very low-price environment. This average for 2020 production is deceptively high and is largely buoyed by Q1, with the precipitous fall in Q2 held for the rest of the year. In 2021, global liquids supply is expected to experience a modest growth of $1.2 \mathrm{MMb} / \mathrm{d}$, reaching $94.4 \mathrm{MMb} / \mathrm{d}$ as prices rise slightly. The 2021 increase in supply is much less than the 2020 increase in demand, allowing the massive increase in inventories accumulated in 2020 to be worked through

The recent cuts agreed by OPEC+, consisting of an initial $9.7 \mathrm{MMb} / \mathrm{d}$ in May, then shifting to approximately $8 \mathrm{MMb} / \mathrm{d}$ until the end of 2020, and followed by about a $6 \mathrm{MMb} / \mathrm{d}$ cut until the end of Q2 2021, are the largest balancing effort ever attempted in the oil market.

The impact of these cuts will not balance the market entirely in 2020, but it will stabilize prices (even if at a low level) and try to prevent storage from overflowing. The low-price environment will also have an outsized impact on non-OPEC players, particularly in 2021, with natural declines in production and voluntary shutdowns offsetting the later reduced cuts from OPEC+.

Geopolitical challenges are expected to be primarily domestic for the foreseeable future, as countries manage the COVID-19 crisis within their own borders. A return to normalcy, with a demand rebound, improved pricing, and resumed production and revenues is a common goal, so it is not expected that downward production pressures will exceed those we are currently experiencing.

Tight oil (largely in the U.S. but with small contributions from Canada and Argentina) is expected to take a significant hit from the current crisis. New development will decrease sharply, and a 'wait and see' attitude will allow for a decline of $1.56 \mathrm{MMb} / \mathrm{d}$ in 2020, with a more modest fall of $300 \mathrm{~Kb} / \mathrm{d}$ in 2021 . The prolonged low-price environment will mean that drilling will occur but production is unlikely to compensate for declining supply. Including the cuts from OPEC+, we expect to see an overall decline in conventional crudes for 2020 of $4.9 \mathrm{MMb} / \mathrm{d}$, and a rebound of $700 \mathrm{~Kb} / \mathrm{d}$ on the back of the assumed moderation of cuts in 2021 while prices slowly recover. We also expect to see unconstrained oil producers further respond to low prices and storage constraints, as has already been observed in Brazil,

Venezuela, Iraq, and Canada.

Discussions on lifting the sanctions on Iran and Venezuela are primarily focused on the humanitarian and medical supply aspects. They do not appear to change our prior expectations concerning oil production.

In this quarterly outlook, we assume that the OPEC+ production cuts are maintained as planned for 2020 and may be relaxed slightly as prices adjust slowly upward in 2021.

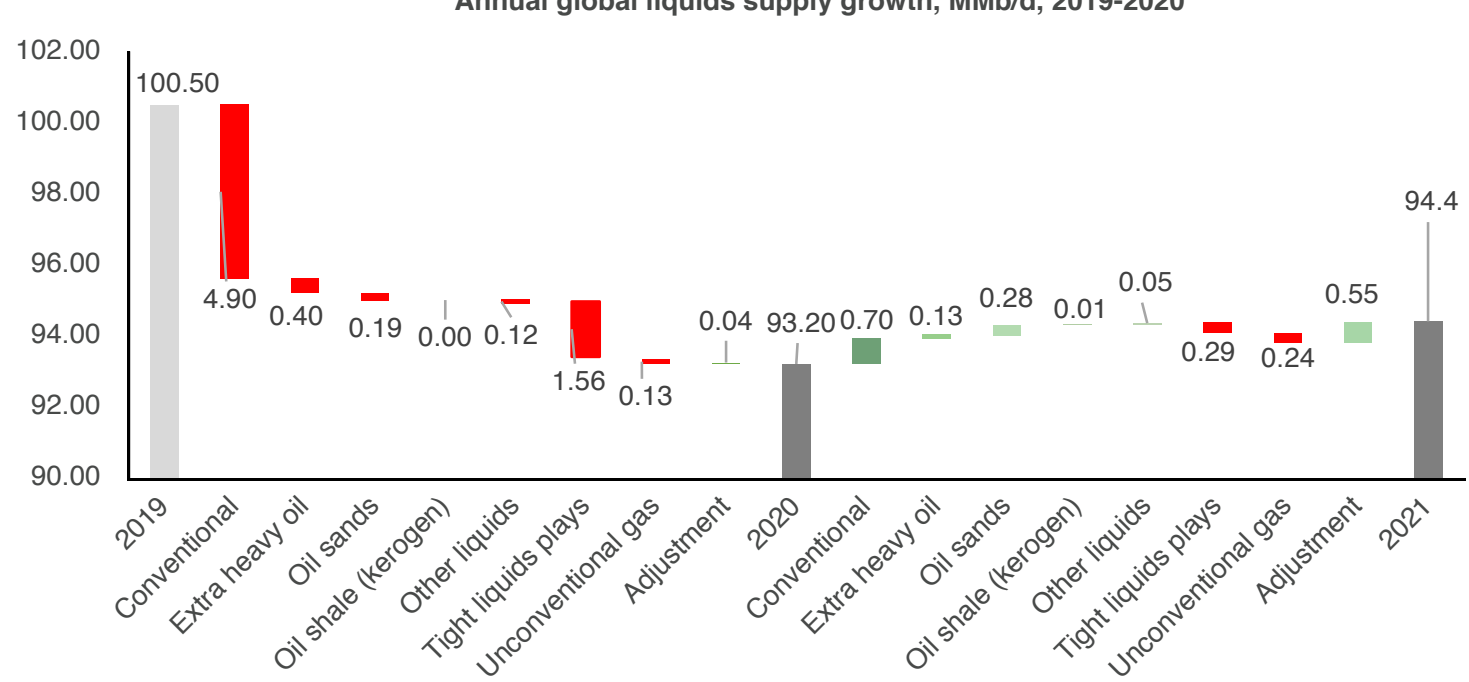

Source: Rystad; KAPSARC, April 2020. 


\section{OPEC+} the history of OPEC. These cuts, and the extraordinary circumstances of their application, are necessary to balance the market, or at least prevent storage from filling completely.

According to reports, the percentage cuts for all levels, with an exemption given to Mexico. Both Saudi Arabia and Russia were given cut reference levels of $11 \mathrm{MMb} / \mathrm{d}$, while the targets for other member countries

The seriousness of the demand imbalance means that compliance is likely to be high initially, but it may be more difficult to maintain the commitment of individual members over time. As is usually the case, we will likely see over-compliance from some core members to counteract minor under-compliance elsewhere, ensuring the overall target is maintained. This has been the case in the recent past. Saudi Arabia, the United Arab Emirates (UAE), and Kuwait are historically the most likely to compensate for the under-compliance of have been reports of these countries' preparations to follow this path if necessary.
OPEC+ are taking cuts to a level not seen before in members are almost equal, based on their production were set close to the levels of previous cut agreements. other members in order to meet the overall target. There
Members of OPEC exempt from the cuts are wildcards: Venezuela and Iran are currently under sanctions, and Libya is experiencing domestic unrest. We have assumed that Libya is likely to return to recent levels of production within the year, but it will return to a stressed market. The U.S. is unlikely to change its sanctions on Iran and Venezuela to allow oil exports, unless there is a change of leadership in the States.
Due to current prices, OPEC+ countries have minor differences concerning natural declines in production and are now assumed to move in lockstep until the agreement nears its end in early 2022.

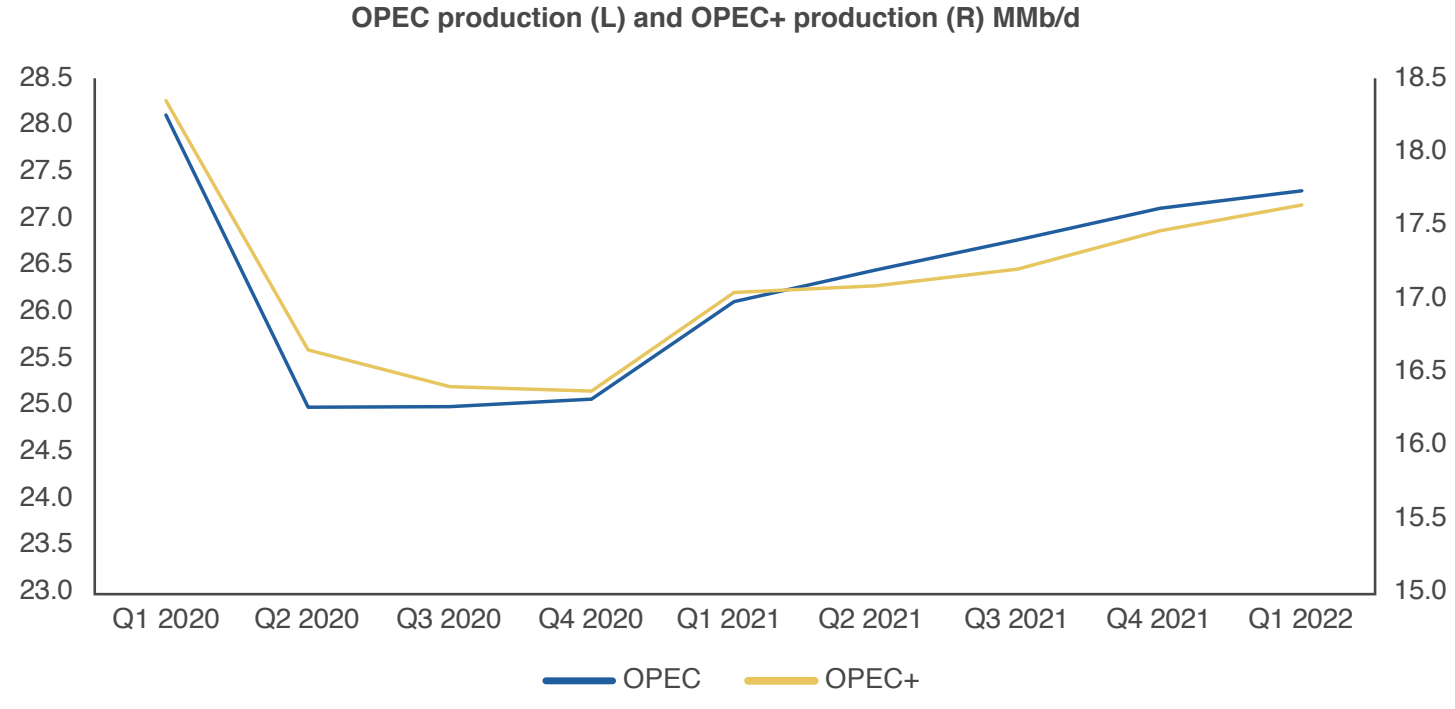

Source: KAPSARC, April 2020 


\section{OPEC+ spare capacity}

OPEC spare capacity, a key element in ensuring market stability, is expected to increase sharply from 2.63 MMb/d to 5.34 MMb/d in only one quarter. OPEC partners see a similar jump from $0.42 \mathrm{MMb} / \mathrm{d}$ to $1.97 \mathrm{MMb} / \mathrm{d}$ in the same period.

As we move into Q3 2020, OPEC's spare capacity is expected to increase further as it cuts $8 \mathrm{MMb} / \mathrm{d}$ for the quarter, more per month than the $9.7 \mathrm{MMb} / \mathrm{d}$ cut agreed for two months as part of the OPEC++ agreement.

This pushes OPEC's spare capacity to approximately $7.7 \mathrm{MMb} / \mathrm{d}$ until the end of 2020 .

For 2021, these cuts are assumed to gradually decline to $6.3 \mathrm{MMb} / \mathrm{d}$, as OPEC+ compliance may falter with rising prices, and some members may face difficulties meeting budgets.

Note: The definition of spare capacity here is based on the target cuts of the current OPEC++ agreement. Additional capacity in Saudi Arabia, stated as either $12 \mathrm{MMb} / \mathrm{d}$ or $12.5 \mathrm{MMb} / \mathrm{d}$, would add either $1 \mathrm{MMb} / \mathrm{d}$ or $1.5 \mathrm{MMb} / \mathrm{d}$ to the figures across the entire chart.
OPEC spare capacity, MMb/d

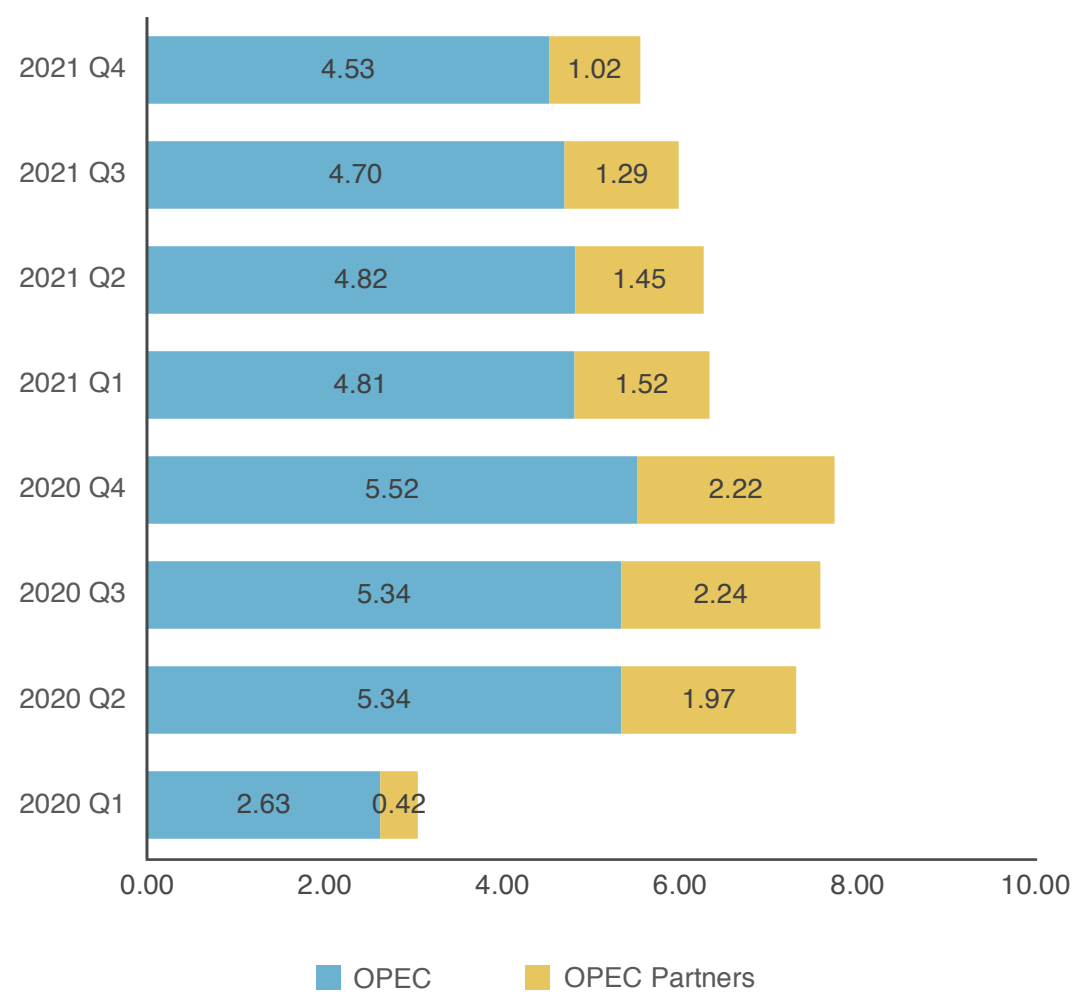

Sources: Rystad; KAPSARC, April 2020. 


\section{OPEC+ assumed supply changes for 2020 and 2021}

\begin{tabular}{l|c|c} 
& $\mathbf{2 0 2 0}$ & $\mathbf{2 0 2 1}$ \\
\hline Bahrain & -5.21 & 3.25 \\
\hline Brunei & -5.37 & -7.65 \\
\hline Sudan & -11.56 & 0.82 \\
\hline Equatorial Guinea & -23.56 & 6.85 \\
\hline Gabon & -37.90 & -0.73 \\
\hline Oman & -48.80 & 11.45 \\
\hline South Sudan & -49.30 & -15.99 \\
\hline Malaysia & -55.11 & -0.27 \\
\hline Congo & -58.49 & 6.91 \\
\hline Azerbaijan & -78.65 & 14.95 \\
\hline Mexico & -83.20 & -4.69 \\
\hline Algeria & -156.55 & 15.27 \\
\hline Nigeria & -168.98 & 1.16 \\
\hline Kazakhstan & -171.46 & -18.31 \\
\hline Angola & -173.23 & -9.83 \\
\hline Venezuela & -185.79 & 124.82 \\
\hline Iran & -282.37 & 31.65 \\
\hline Kuwait & -328.35 & 35.30 \\
\hline UAE & -413.50 & -43.58 \\
\hline Libya & -526.41 & 219.38 \\
\hline Saudi Arabia & -614.14 & 299.15 \\
\hline Iraq & -744.86 & 111.40 \\
\hline Russia & -823.63 & 269.31 \\
\hline TOTAL PARTNER & -1315.55 & 252.87 \\
\hline OPEC & -3725.99 & 755.86 \\
\hline & & \\
\hline & & \\
\hline
\end{tabular}

\begin{tabular}{c|c} 
& $\mathrm{Kb} / \mathrm{d}$ \\
\hline & 50 \\
\hline & 0 \\
\hline & -50 \\
\hline & -100 \\
\hline & -400
\end{tabular}




\section{Non-OPEC+}

Non-OPEC production and Brent crude oil prices

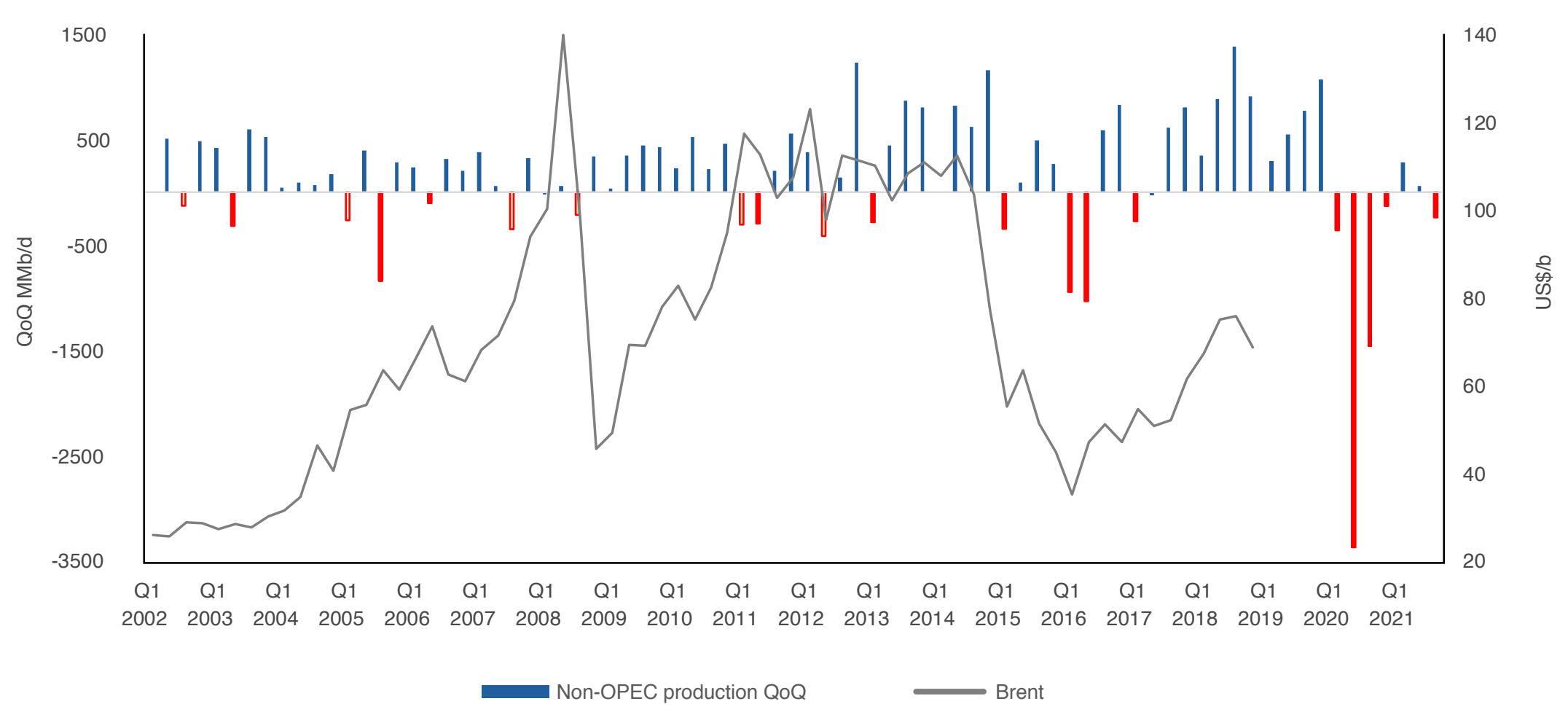

\section{Non-OPEC+ growth:}

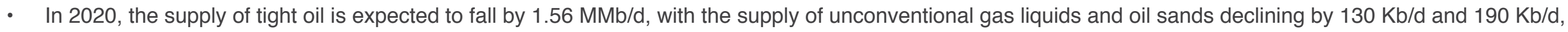
respectively.

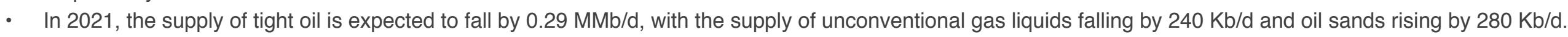

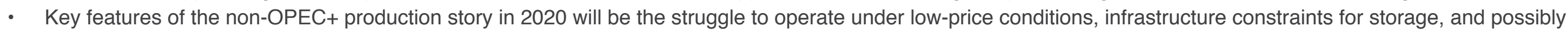
defending domestic demand. 


\section{Non-OPEC (tight oil)}

Tight oil is in a precarious position. Economic conditions in the United States have made it difficult to access funding and sell the oil. Before the COVID-19 pandemic, it was already forecast that growth in 2020 would be half that of 2019. However, the economic downturn precipitated by COVID-19 is now likely to be far worse than the financial crisis of 2008-2009.

Some major bankruptcies have already occurred, and there will likely be more distressed companies subject to bankruptcy, merger or acquisition in the short run. Some support, in the form of filling the U.S. Strategic Petroleum Reserve, may be helpful. However, that measure alone cannot maintain the industry.

The fundamental price environment is too low for shale, despite the great strides in its technology and cost reductions associated with its production of the last few years. Until the value of West Texas Intermediate rises to about $\$ 45 / b$, we do not expect to see true growth to return to the shale industry.

Current low prices and infrastructure pushback appear to be forcing shale production into a steady decline, with a fall of $1.56 \mathrm{MMb} / \mathrm{d}$ in 2020, and a further 300 $\mathrm{Kb} / \mathrm{d}$, despite some price recovery. Non-U.S. producers, such as Argentina and Canada, may see the entirety of their production halted in this period, as they are not as efficient as their U.S. counterparts, and, as a result, have higher overheads.
Added pipeline capacity will likely be put on hold indefinitely unless it is already close to completion.

Existing pipelines may find themselves underutilized as storage fills up, and there is no place to send production.
Investors may also begin withholding cash as the crisis continues, due to their other obligations or more attractive investment opportunities elsewhere.

Monthly U.S. drilling activity (L) vs. global shale production (MMb/d) (R)

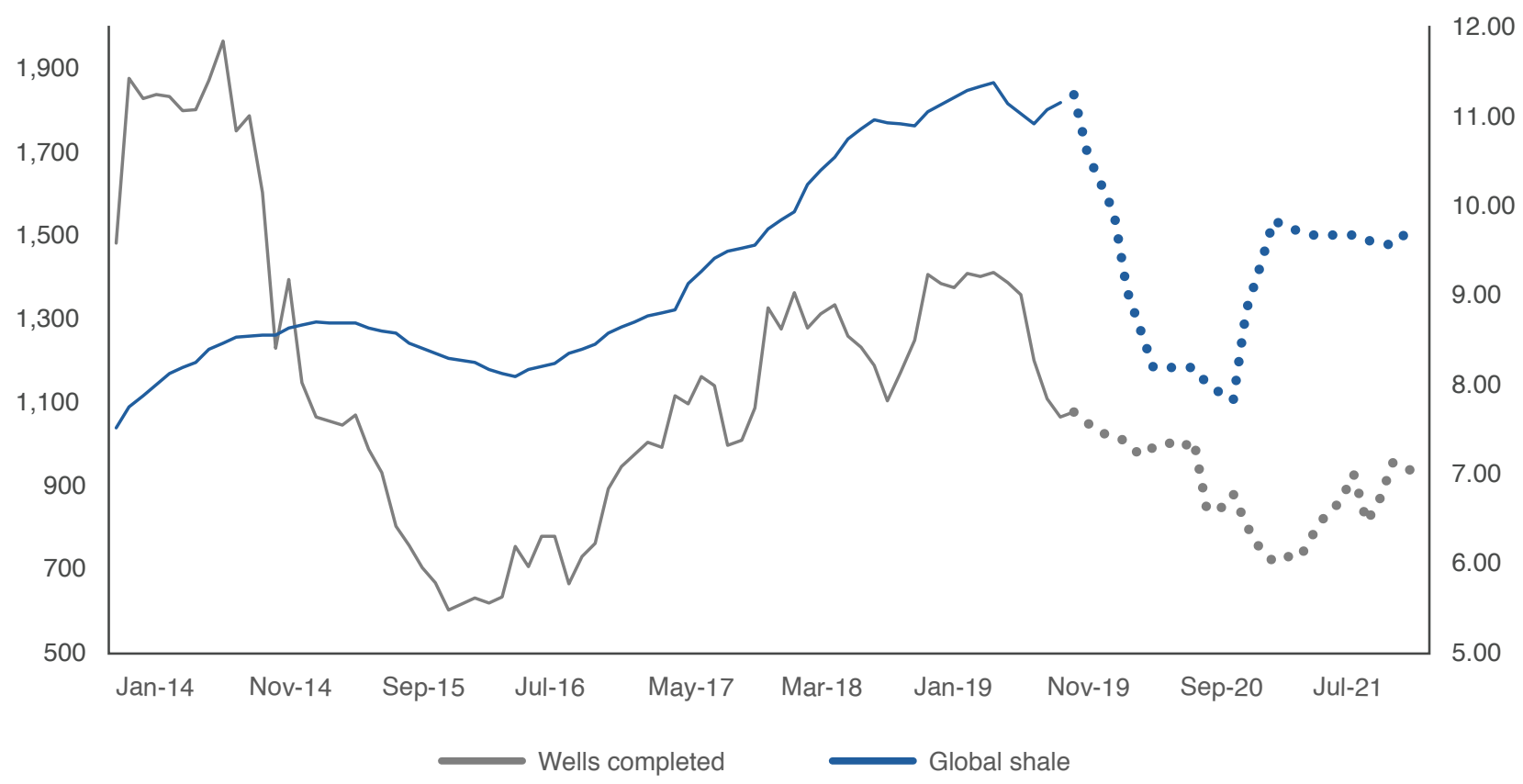

Productivity Report, EIA, April 9, 2020.

2020 - 2021 KAPSARC, April 2020. 


\section{Balances in the time of COVID-19...}

Our assessment shows that, over the next eight quarters, the market is likely to start with a major surplus and have a deficit by Q3 2020, which will force inventories to decline. KOMO predicts an average global surplus of $520 \mathrm{~Kb} / \mathrm{d}$ throughout 2020 and an average deficit of $3.9 \mathrm{~Kb} / \mathrm{d}$. This assessment is predicated on the basis that OPEC+ members will adhere to the OPEC++ agreement post-2020. However, it may be possible to balance the market by the beginning of 2021 through lower cuts, depending on inventory levels.

We anticipate that cuts focused on conventional oil will produce a YoY decline in production of $4.9 \mathrm{MMb} / \mathrm{d}$. However, tight oil production will struggle the most in 2020. It was estimated in January that U.S. shale was already facing difficulties and would grow by a mere 1 $\mathrm{MMb} / \mathrm{d}$ during the year, despite prices of around $\$ 60 / \mathrm{b}$. However, given the situation now, shale's difficulties have only accelerated. This will allow more conventional oil to come on stream than previously expected in 2021. If current trends continue and stocks are unable to be withdrawn any faster, and shale production further declines in 2021, then OPEC+ members may be required to cut less in order to balance the markets. KOMO predicts that, due to the low-price environment, it is not only shale that will face investment-driven declines, but the majority of producers worldwide. As a result, OPEC+ members may have the opportunity to reverse their cuts.
Indeed, if OPEC+ members kept production levels similar to those of 2019, the market surplus could surpass $5 \mathrm{MMb} / \mathrm{d}$ in 2020. However, the market would balance in 2021 because many other producers would cease to produce if prices collapsed even further. In all scenarios, this balancing act is expected to create a favorable environment for prices to rise eventually, albeit slowly.
Though there will still be an annual surplus for 2020 , KOMO estimates that environmental fundamentals will become favorable for producers around Q3 or Q4 2020 and in 2021. The market surplus is estimated to peak by Q2 2020 at $7 \mathrm{MMb} / \mathrm{d}$, before dropping to a deficit in Q3 2020. Nevertheless, a substantial deficit for a few quarters should be necessary in order to reduce inventories, which are now building dramatically.

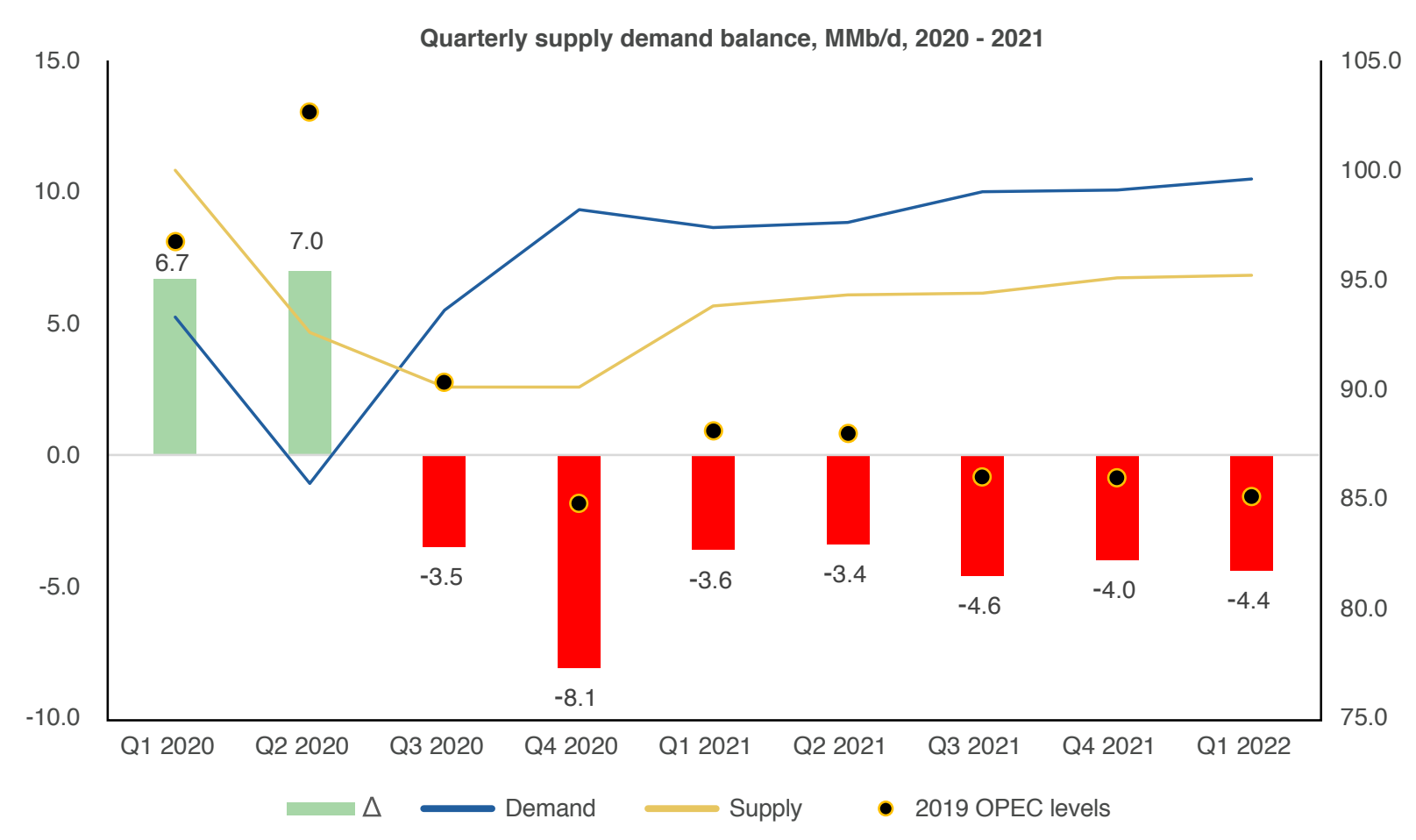

Source: KAPSARC, April 2020 


\section{Price fundamentals (inventories)}

Inventory behavior will indicate the direction of price movements. Preliminary data for April 2020 shows continued growth in real OECD inventories. Target inventories in the KOMO model are expected to stagnate due to several downward risk factors, including fears of a prolonged COVID-19 pandemic, a reduction in investment, as well as the focus of countries on health systems rather than energy security. As a result, shrinking demand indicates that the original 'target' rate is overestimated.

In this outlook, inventories are expected to grow sharply in the first half of 2020 but should tighten as we enter 2021. We currently expect real OECD inventories to surpass target inventories for 2020 and create storage challenges (i.e., actual and floating very large crude carrier [VLCC] storage capacity) during the first half of the year. High inventories indicate bearish prices and vice versa. Consequently, KOMO expects that the strong OPEC++ cuts will begin to rebalance inventories, resulting in slowly rising prices over the next eight quarters.

How high inventories could go is an important question. Reaching the absolute limit would produce a heavy downward price signal that would force mass shutdowns. This situation has never occurred before, but there is a possibility of this occurring in these unprecedented market conditions.
The KOMO model estimates that real OECD inventories will grow by $280 \mathrm{MMb}$ in 2020 then decline by 540

MMb in 2021. Target inventories, on the other hand, are

expected to stagnate in 2020 , as geopolitical risk factors are presumed to dissipate, before growing by a sluggish $26 \mathrm{MMb}$ in 2021.

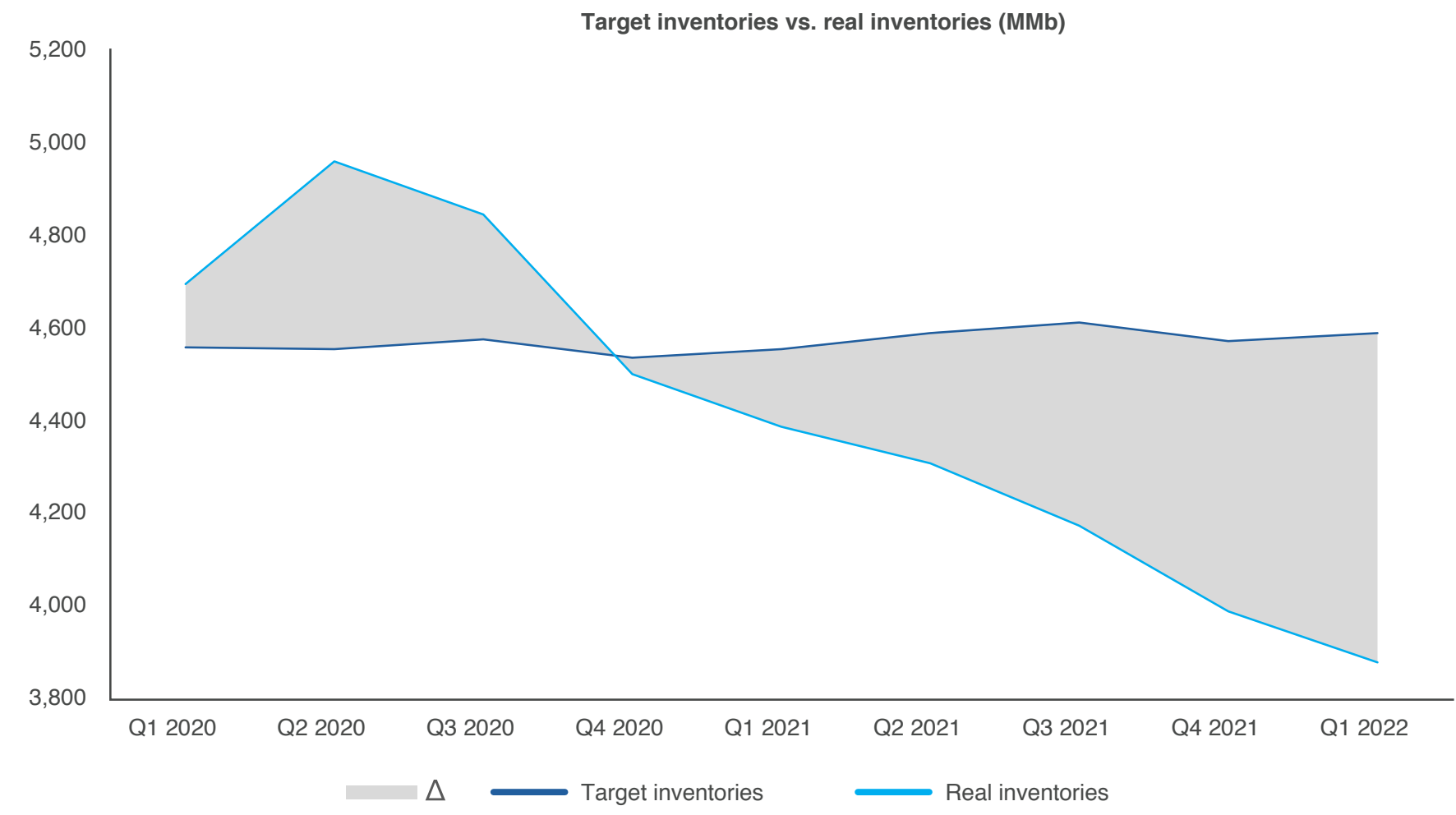

Sources: EIA; KAPSARC, January 2020. 


\section{Price fundamentals (Brent)}

\begin{tabular}{|c|c|c|c|c|c|c|c|c|c|c|c|}
\hline & Q2 2020 & Q3 2020 & Q4 2020 & Q1 2021 & Q2 2021 & Q3 2021 & Q4 2021 & Q1 2022 & & 2020 & 2021 \\
\hline Bloomberg & 30.00 & 35.31 & 41.32 & 46.81 & 47.74 & 50.45 & & & Bloomberg & 39.13 & 49.09 \\
\hline Market sentiment & 57.60 & 58.00 & 61.66 & 64.50 & 64.50 & 66.00 & 59.00 & 65.00 & Market sentiment & 56.82 & 63.50 \\
\hline
\end{tabular}

Source: Bloomberg,April 14, 2020.

*Market sentiment is based on publicly available forecast data.

KOMO Brent forecast vs. balances and forward curve

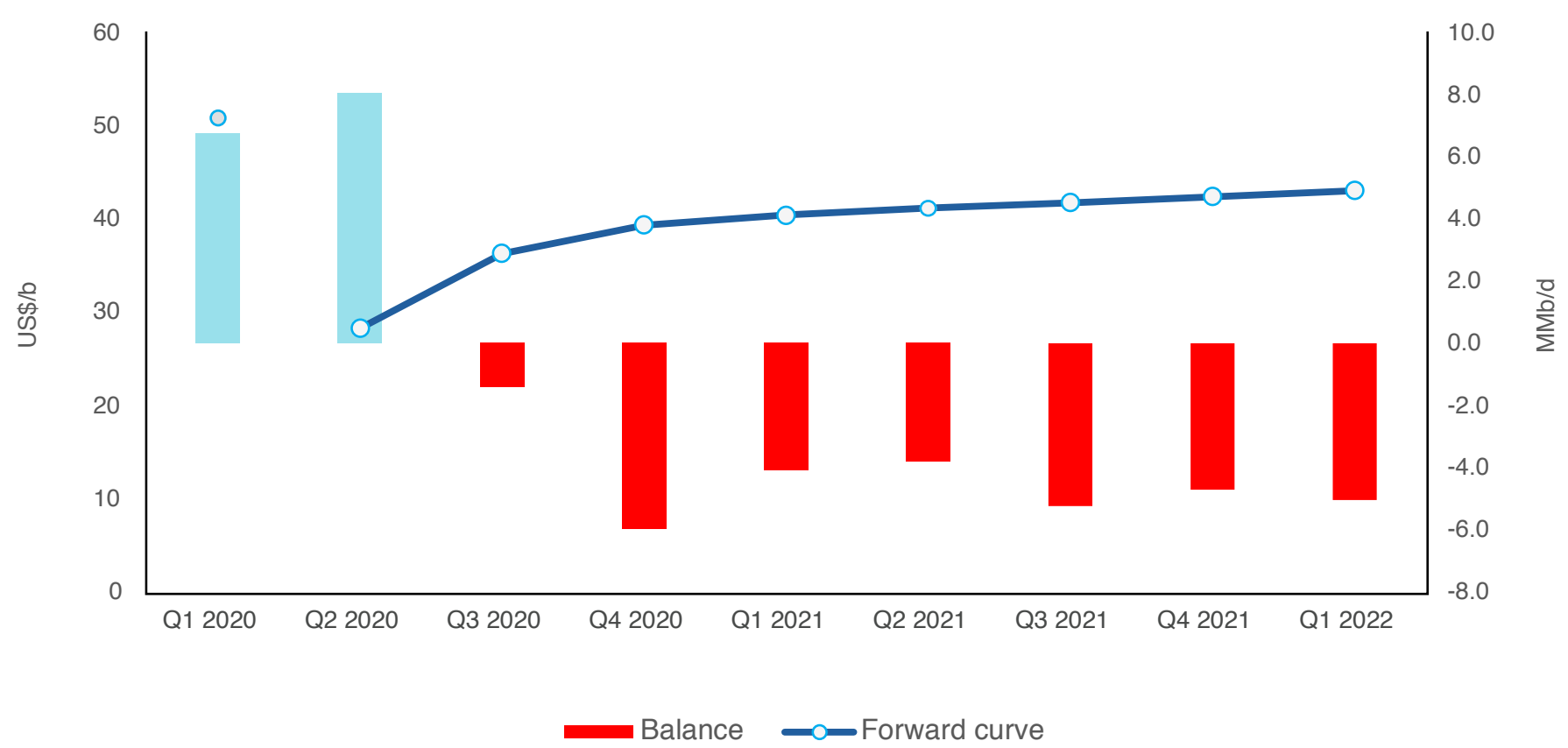




\section{Price fundamentals (forward and future curves)}

The graph below depicts confidence intervals derived from options market information for at-the-money options contracts.

The graphs represent boundaries calculated at $50 \%$, $68 \%$ and $95 \%$ confidence intervals.

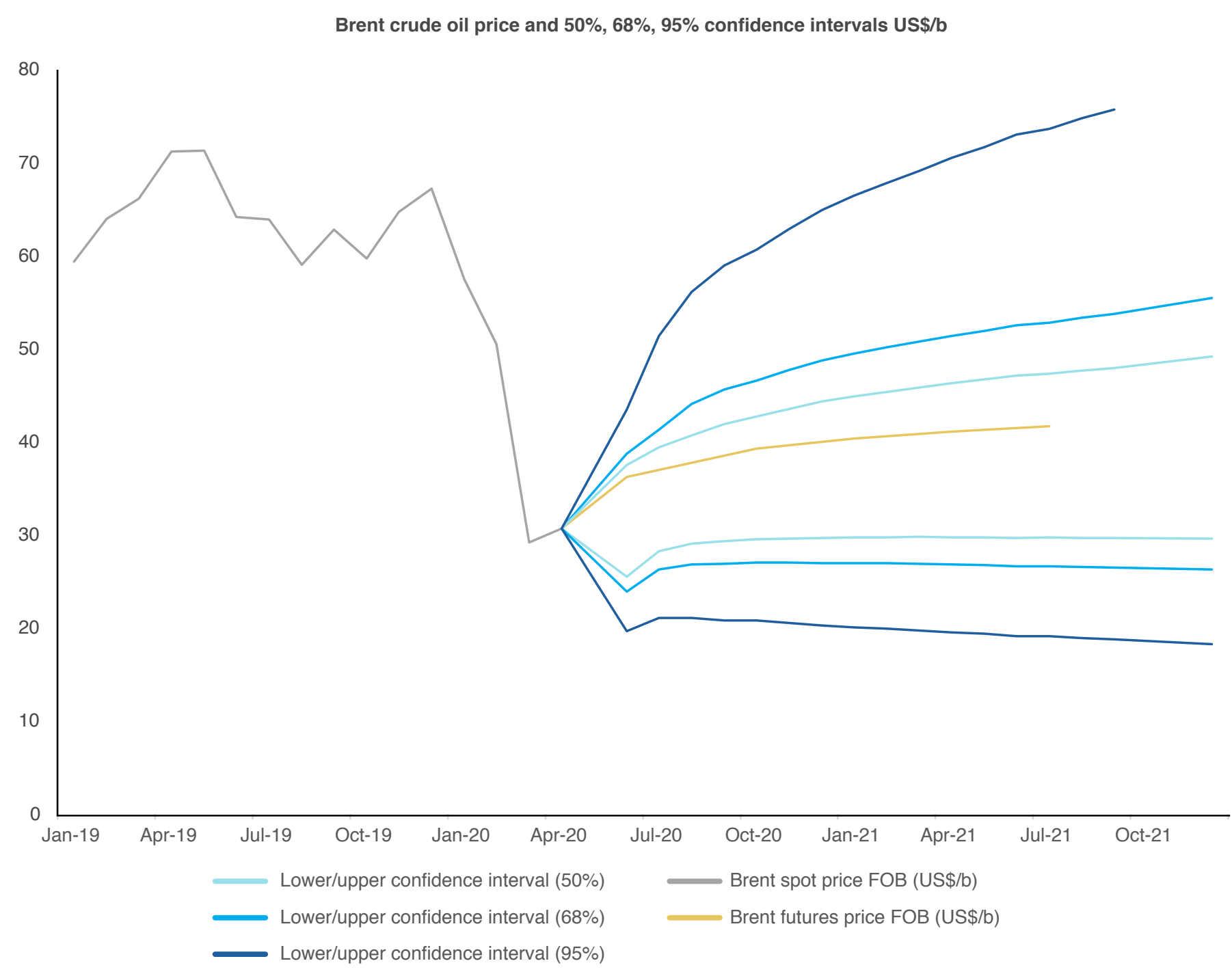




\section{Price fundamentals (markets)}

Hedging pressure (HP): The graph below shows the settlement price for Brent against hedging pressure. Hedging pressure is a measure of physical commercial (producers/merchants/processors/users) net short positions relative to net managed money long positions. It indicates a negative relationship between Brent prices and market hedgers. The fact that HP continues to decline indicates that the market remains unsettled by the OPEC++ cuts and believes that prices may stagnate or continue to decline.

Trader class shares: Based on the trader class shares data, money managers have reduced their long positions due to the low oil price environment, while producers and swap dealers are taking more long positions to cover for the reduction in long positions. Nevertheless, it is expected that money manager long positions will increase gradually as prices rise.
Weekly hedging pressure (L) vs. ICE Brent price (R)

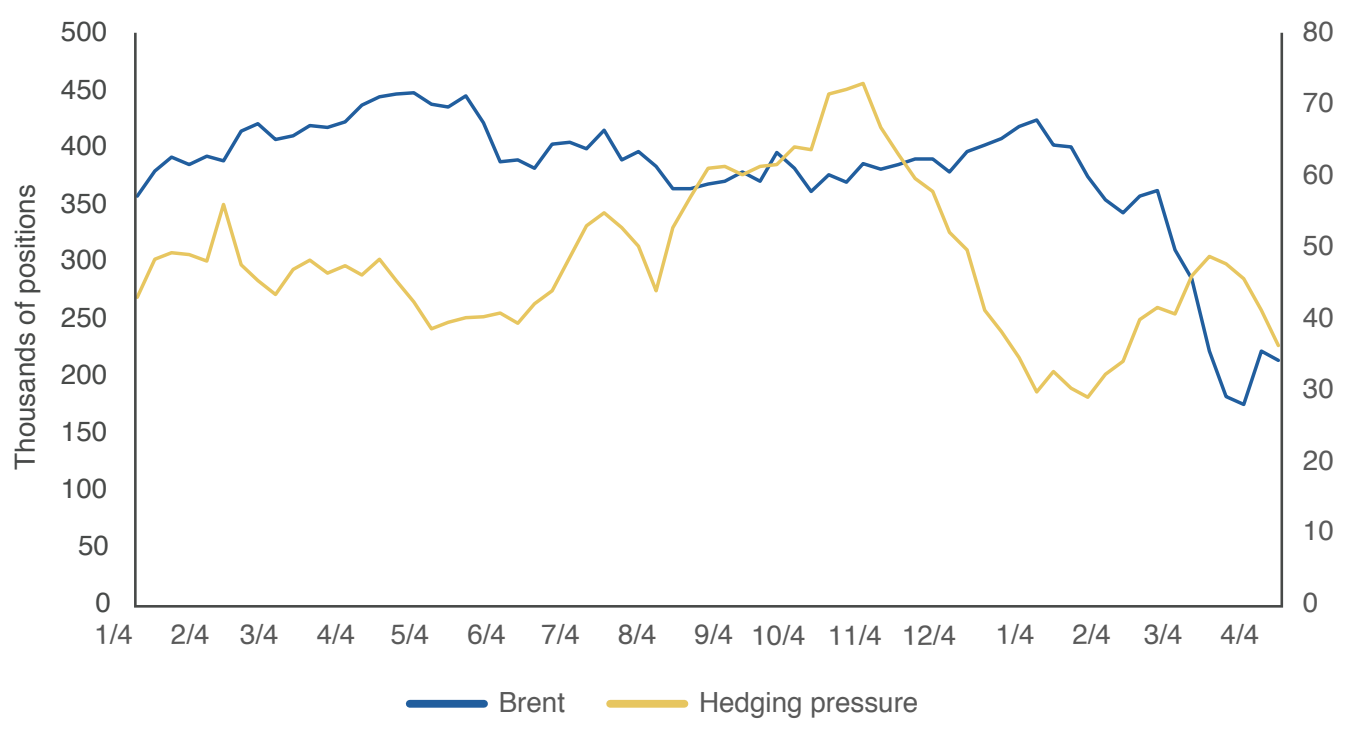

Trader class shares of long and shorts

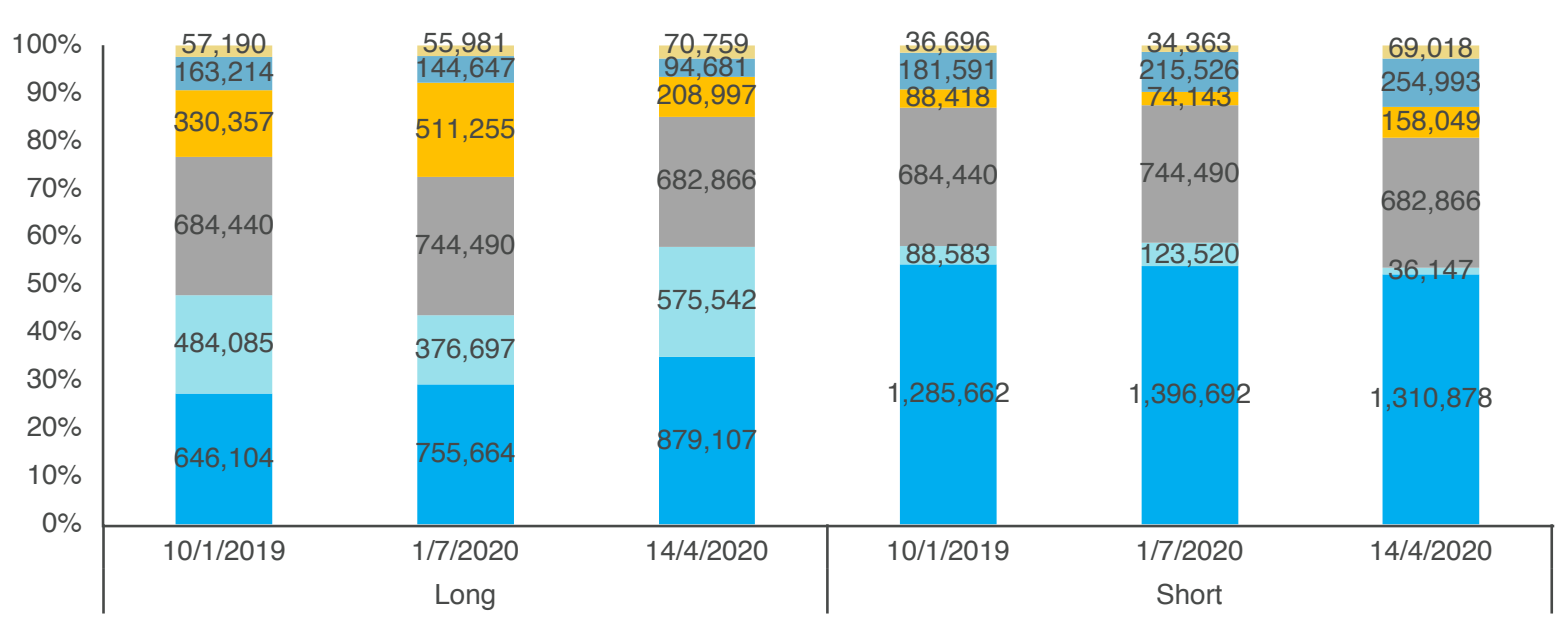

$\square \mathrm{PM} \backsim \mathrm{SW} \backsim$ Spread $\backsim \mathrm{MM} \backsim \mathrm{OR} \backsim \mathrm{NR}$ 


\section{Price fundamentals (markets)}

As the U.S. Dollar Index continues to decline due to the current recession, along with inflation, demand for Brent is not expected to rise, except in countries that are recovering from the COVID-19 pandemic, i.e., in China.

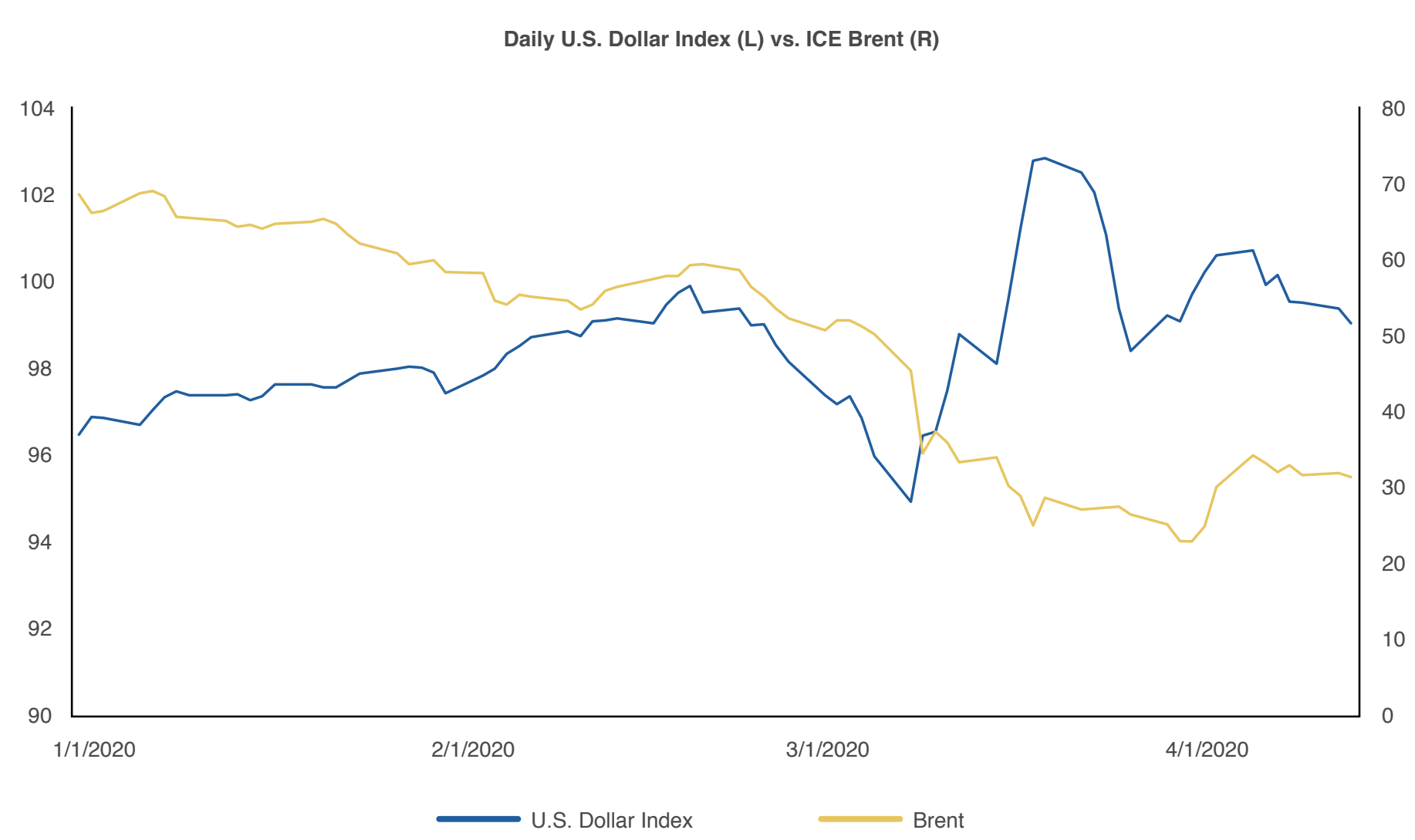




\section{Editorial: Holding our breath for a world post-COVID-19...}

Forecasting the oil market requires knowledge of how the world normally works. There is a wide array of challenges when producing, refining, transporting, and selling products based on consumer needs and pocketbooks. Sometimes we need to statistically account for the probability of disruptions, up to and including geopolitical tensions. But this is not a normal market. The level of impact on the demand side is so far beyond usual disruptions, making this period a 'black swan' event.

Black swan events, highly unlikely events that have a large impact when they do occur, are so unpredictable and originate from such unexpected places that it is impractical to prepare for them. Leading up to 2008 (YoY $-0.1 \%$ GDP), few thought that the U.S. housing market would collapse, let alone infect the rest of the global economy. Very few people thought about this pandemic seriously. We may have assumed that in the intervening 100 years since the Spanish Flu, our advances in healthcare would prevent this kind of event, but that has not been the case. Interestingly, this pandemic has not caused the same response as the cholera outbreak of $1895 \mathrm{did}$. The latter resulted in an increase in crude oil prices as many oil industry employees could not get to work. If this had been the case in 2020, OPEC+ might not have needed to cut and instead would be trying to raise production.
So now, we have an abnormal market driven by non-price-related factors that cannot be understood through conventional economic analysis. These include policy-related factors such as viral spread probabilities, quarantine timeframes, government responses, consumer behavior in times of stress, physical limitations on storage, and the ultimate impact of COVID-19 on the global economy.

Consumers and producers would like nothing better than to return to a pre-COVID-19 world next week. If we could be reasonably certain of our safety and that of ou loved ones, then it would be entirely possible, but this is currently not the case. As a result, global GDP growth, estimated at $+3 \%$ in January, is likely to reach $-3 \%$, as stated by the IMF, which would be by far the biggest decline since the Great Depression.

Even if we were to return to a less restricted world, some sources of demand might never return and some supply chains may never recover. Indeed, the IMF is expecting a rise in unemployment in advanced economies of around 8.3\%. CNBC reported on March 30 that "Economists at the Fed's St. Louis district project total employment reductions of 47 million, which would translate to a $32.1 \%$ unemployment rate." Working from home has been a growing trend for years, and some of the companies trying it out right now might choose to continue. Business trips may not seem so necessary if video conferencing becomes second nature. Some conferences may migrate to online meetings. This would translate to big gains for the tech industry and possible losses for the transport industry. These are the changes that will impact the world of work alone. The far-reaching impacts of the COVID-19 pandemic on other areas of people's lives are even harder to anticipate.

The COVID-19 pandemic may subside in a few months - if we are fortunate - but how we go about our daily lives may have been greatly altered. Future oil demand might be reduced as we come to realize, for example, that the substitutes for travel, among other needs, we have become used to are adequate. Investments in renewable energy are likely also to be affected, leading to additional uncertainty surrounding the future energy mix.

Our final message in the Q1 report was, "If there is one message for 2020, it should be one of cooperation and complementarity between sources of energy and energy producers." Somehow this statement seems as relevant now as it was in January. 



\begin{tabular}{|c|c|c|c|c|c|c|c|c|c|c|c|c|c|c|}
\hline & & & 2019 & Q1 & Q2 & Q3 & Q4 & 2020 & Q1 & Q2 & Q3 & Q4 & 2021 & Q1 \\
\hline \multirow{11}{*}{ Americas } & \multirow{5}{*}{ OECD } & United States & 20.9 & 20.1 & 16.4 & 18.4 & 19.9 & 18.7 & 19.8 & 19.7 & 19.9 & 19.9 & 19.8 & 19.8 \\
\hline & & Canada & 2.4 & 2.5 & 2.4 & 2.5 & 2.4 & 2.5 & 2.5 & 2.4 & 2.4 & 2.4 & 2.4 & 2.5 \\
\hline & & Mexico & 2.0 & 1.9 & 1.7 & 1.8 & 1.9 & 1.8 & 1.9 & 1.9 & 1.9 & 1.9 & 1.9 & 1.9 \\
\hline & & Chile & 0.4 & 0.4 & 0.4 & 0.4 & 0.3 & 0.4 & 0.4 & 0.5 & 0.4 & 0.4 & 0.4 & 0.4 \\
\hline & & Total & 25.6 & 24.9 & 20.9 & 23.0 & 24.5 & 23.4 & 24.6 & 24.5 & 24.7 & 24.6 & 24.6 & 24.6 \\
\hline & \multirow{5}{*}{ Non-OECD } & Argentina & 0.7 & 0.7 & 0.6 & 0.7 & 0.7 & 0.7 & 0.7 & 0.8 & 0.8 & 0.8 & 0.8 & 0.8 \\
\hline & & Brazil & 3.1 & 3.1 & 2.9 & 3.1 & 3.2 & 3.1 & 3.1 & 3.1 & 3.2 & 3.2 & 3.2 & 3.1 \\
\hline & & Venezuela & 0.4 & 0.3 & 0.3 & 0.3 & 0.3 & 0.3 & 0.2 & 0.2 & 0.2 & 0.2 & 0.2 & 0.2 \\
\hline & & RO Latin America & 2.3 & 2.2 & 2.1 & 2.2 & 2.3 & 2.2 & 2.2 & 2.3 & 2.3 & 2.3 & 2.3 & 2.3 \\
\hline & & Total & 6.4 & 6.3 & 5.9 & 6.3 & 6.5 & 6.2 & 6.3 & 6.4 & 6.5 & 6.5 & 6.4 & 6.4 \\
\hline & \multicolumn{2}{|c|}{ Total Americas } & 32.1 & 31.2 & 26.8 & 29.3 & 31.0 & 29.6 & 30.9 & 30.9 & 31.2 & 31.1 & 31.0 & 30.9 \\
\hline \multirow{7}{*}{ Europe } & \multirow{6}{*}{ OECD } & Germany & 2.4 & 2.3 & 2.1 & 2.4 & 2.5 & 2.3 & 2.3 & 2.3 & 2.4 & 2.4 & 2.4 & 2.3 \\
\hline & & France & 1.7 & 1.6 & 1.5 & 1.6 & 1.6 & 1.6 & 1.8 & 1.7 & 1.8 & 1.7 & 1.7 & 1.8 \\
\hline & & United Kingdom & 1.6 & 1.6 & 1.5 & 1.5 & 1.5 & 1.5 & 1.5 & 1.6 & 1.6 & 1.6 & 1.6 & 1.6 \\
\hline & & Poland & 0.7 & 0.7 & 0.6 & 0.7 & 0.6 & 0.6 & 0.6 & 0.6 & 0.7 & 0.7 & 0.6 & 0.6 \\
\hline & & Turkey & 1.0 & 1.0 & 0.8 & 0.8 & 0.7 & 0.8 & 0.7 & 0.8 & 0.8 & 0.8 & 0.8 & 0.8 \\
\hline & & RO OECD Europe & 7.1 & 5.9 & 5.9 & 6.9 & 7.2 & 6.5 & 6.5 & 6.5 & 6.6 & 6.6 & 6.5 & 6.6 \\
\hline & \multicolumn{2}{|c|}{ Total OECD Europe } & 14.5 & 12.9 & 12.4 & 13.8 & 14.2 & 13.3 & 13.4 & 13.4 & 13.9 & 13.8 & 13.6 & 13.6 \\
\hline \multirow{11}{*}{ Asia-Oceania } & \multirow{5}{*}{ OECD } & Australia & 1.2 & 1.1 & 0.9 & 1.0 & 1.0 & 1.0 & 1.1 & 1.1 & 1.1 & 1.2 & 1.1 & 1.2 \\
\hline & & Japan & 3.7 & 3.8 & 3.2 & 3.4 & 3.8 & 3.5 & 4.1 & 3.4 & 3.6 & 4.0 & 3.8 & 4.2 \\
\hline & & Republic of Korea & 2.5 & 2.5 & 2.1 & 2.3 & 2.5 & 2.4 & 2.6 & 2.4 & 2.5 & 2.7 & 2.5 & 2.7 \\
\hline & & New Zealand & 0.2 & 0.2 & 0.2 & 0.2 & 0.2 & 0.2 & 0.2 & 0.2 & 0.2 & 0.2 & 0.2 & 0.2 \\
\hline & & Total & 7.6 & 7.6 & 6.4 & 6.8 & 7.5 & 7.1 & 7.9 & 7.0 & 7.3 & 8.0 & 7.6 & 8.3 \\
\hline & \multirow{5}{*}{ Non-OECD } & China & 13.3 & 10.6 & 12.1 & 13.4 & 13.7 & 12.4 & 13.7 & 14.0 & 13.8 & 13.9 & 13.9 & 14.0 \\
\hline & & India & 5.0 & 5.0 & 4.2 & 4.6 & 5.0 & 4.7 & 5.2 & 5.2 & 4.9 & 5.3 & 5.1 & 5.5 \\
\hline & & Indonesia & 1.8 & 1.8 & 1.7 & 1.7 & 1.8 & 1.7 & 1.8 & 1.9 & 1.9 & 1.9 & 1.9 & 1.9 \\
\hline & & RO Asia & 7.4 & 7.2 & 6.2 & 6.7 & 7.2 & 6.8 & 7.6 & 7.4 & 7.4 & 7.3 & 7.4 & 7.8 \\
\hline & & Total & 27.5 & 24.6 & 24.2 & 26.4 & 27.6 & 25.7 & 28.3 & 28.4 & 28.0 & 28.3 & 28.3 & 29.2 \\
\hline & \multicolumn{2}{|c|}{ Total Asia } & 35.1 & 32.2 & 30.5 & 33.2 & 35.1 & 32.8 & 36.2 & 35.4 & 35.3 & 36.4 & 35.8 & 37.4 \\
\hline \multirow{13}{*}{ Middle East } & OECD & Israel & 0.3 & 0.2 & 0.2 & 0.2 & 0.2 & 0.2 & 0.3 & 0.3 & 0.3 & 0.2 & 0.3 & 0.3 \\
\hline & \multirow{11}{*}{ Non-OECD } & Bahrain & 0.1 & 0.1 & 0.0 & 0.1 & 0.1 & 0.1 & 0.1 & 0.1 & 0.1 & 0.1 & 0.1 & 0.1 \\
\hline & & Iraq* & 0.9 & 0.9 & 0.8 & 1.0 & 0.9 & 0.9 & 0.7 & 0.7 & 0.8 & 0.8 & 0.7 & 0.8 \\
\hline & & Kuwait & 0.4 & 0.3 & 0.3 & 0.5 & 0.4 & 0.4 & 0.3 & 0.3 & 0.4 & 0.3 & 0.3 & 0.3 \\
\hline & & Oman & 0.2 & 0.2 & 0.2 & 0.2 & 0.2 & 0.2 & 0.2 & 0.2 & 0.2 & 0.2 & 0.2 & 0.2 \\
\hline & & Saudi Arabia & 3.2 & 2.2 & 2.7 & 2.9 & 2.4 & 2.5 & 2.7 & 3.3 & 3.6 & 3.0 & 3.1 & 2.7 \\
\hline & & Qatar & 0.2 & 0.2 & 0.2 & 0.2 & 0.2 & 0.2 & 0.2 & 0.2 & 0.2 & 0.2 & 0.2 & 0.2 \\
\hline & & UAE & 0.9 & 0.9 & 0.8 & 0.9 & 0.9 & 0.9 & 0.9 & 0.9 & 0.9 & 0.9 & 0.9 & 0.9 \\
\hline & & Total GCC & 5.8 & 4.6 & 4.9 & 5.8 & 5.1 & 5.1 & 5.0 & 5.7 & 6.2 & 5.4 & 5.6 & 5.1 \\
\hline & & Iran & 1.9 & 1.8 & 1.4 & 1.4 & 1.9 & 1.6 & 1.9 & 1.9 & 1.8 & 1.8 & 1.8 & 2.0 \\
\hline & & RO Middle East & 0.5 & 0.5 & 0.5 & 0.5 & 0.6 & 0.5 & 0.5 & 0.5 & 0.5 & 0.5 & 0.5 & 0.5 \\
\hline & & Total & 8.3 & 6.9 & 6.8 & 7.7 & 7.5 & 7.2 & 7.3 & 8.1 & 8.6 & 7.8 & 7.9 & 7.6 \\
\hline & \multicolumn{2}{|c|}{ Total Middle East } & 8.6 & 7.1 & 7.1 & 7.9 & 7.8 & 7.5 & 7.6 & 8.3 & 8.8 & 8.0 & 8.2 & 7.9 \\
\hline \multirow{4}{*}{ Africa } & \multirow{3}{*}{ Non-OECD } & Egypt & 0.7 & 0.7 & 0.5 & 0.5 & 0.6 & 0.6 & 0.6 & 0.6 & 0.6 & 0.6 & 0.6 & 0.6 \\
\hline & & South Africa & 0.6 & 0.6 & 0.5 & 0.4 & 0.5 & 0.5 & 0.5 & 0.5 & 0.5 & 0.5 & 0.5 & 0.6 \\
\hline & & Other Africa & 2.7 & 2.9 & 2.7 & 2.6 & 3.1 & 2.8 & 2.9 & 2.9 & 2.6 & 2.9 & 2.8 & 3.0 \\
\hline & \multicolumn{2}{|c|}{ Total Africa } & 4.0 & 4.2 & 3.7 & 3.5 & 4.2 & 3.9 & 4.0 & 4.0 & 3.7 & 4.0 & 3.9 & 4.1 \\
\hline & & Russia & 3.7 & 3.6 & 3.0 & 3.5 & 3.7 & 3.5 & 3.6 & 3.6 & 3.9 & 3.8 & 3.7 & 3.7 \\
\hline Eurasia & Non-OECD & RO Eurasia & 2.1 & 1.9 & 2.1 & 2.3 & 2.2 & 2.1 & 1.8 & 2.0 & 2.2 & 2.1 & 2.0 & 1.9 \\
\hline & & asia & 5.7 & 5.5 & 5.1 & 5.8 & 5.9 & 5.6 & 5.4 & 5.6 & 6.1 & 5.9 & 5.7 & 5.6 \\
\hline
\end{tabular}




\begin{tabular}{|c|c|c|c|c|c|c|c|c|c|}
\hline & Q1 2020 & Q2 2020 & Q3 2020 & Q4 2020 & Q1 2021 & Q2 2021 & Q3 2021 & Q4 2021 & Q1 2022 \\
\hline Conventional & 73.25 & 68.19 & 67.60 & 67.64 & 69.30 & 69.56 & 69.78 & 70.20 & 70.28 \\
\hline Extra heavy oil & 3.90 & 3.58 & 3.52 & 3.55 & 3.65 & 3.74 & 3.79 & 3.90 & 3.97 \\
\hline Oil sands & 2.90 & 2.53 & 2.58 & 2.65 & 2.81 & 2.93 & 3.00 & 3.04 & 3.05 \\
\hline Oil shale (kerogen) & 0.02 & 0.02 & 0.02 & 0.03 & 0.03 & 0.03 & 0.03 & 0.03 & 0.04 \\
\hline Other liquids & 5.78 & 5.61 & 5.53 & 5.59 & 5.60 & 5.66 & 5.69 & 5.78 & 5.80 \\
\hline Tight liquids plays & 11.23 & 9.91 & 8.17 & 8.18 & 7.81 & 9.83 & 9.66 & 9.66 & 9.54 \\
\hline Unconventional gas & 2.95 & 2.80 & 2.64 & 2.57 & 2.49 & 2.53 & 2.49 & 2.50 & 2.50 \\
\hline Adjustment & - & - & - & $(0.14)$ & 2.07 & - & - & - & - \\
\hline \multirow{2}{*}{ Total } & 100.02 & 92.64 & 90.07 & 90.07 & 93.75 & 94.28 & 94.44 & 95.11 & 95.18 \\
\hline & Q1 2020 & Q2 2020 & Q3 2020 & Q4 2020 & Q1 2021 & Q2 2021 & Q3 2021 & Q4 2021 & Q1 2022 \\
\hline Algeria & 1.02 & 0.82 & 0.86 & 0.86 & 0.91 & 0.91 & 0.92 & 0.93 & 0.94 \\
\hline Angola & 1.36 & 1.19 & 1.25 & 1.25 & 1.28 & 1.26 & 1.24 & 1.23 & 1.22 \\
\hline Congo & 0.30 & 0.25 & 0.27 & 0.27 & 0.27 & 0.28 & 0.28 & 0.28 & 0.28 \\
\hline Ecuador & 0.54 & 0.52 & 0.51 & 0.50 & 0.49 & 0.48 & 0.47 & 0.46 & 0.46 \\
\hline Equatorial Guinea & 0.12 & 0.10 & 0.10 & 0.11 & 0.11 & 0.11 & 0.11 & 0.11 & 0.09 \\
\hline Gabon & 0.20 & 0.14 & 0.15 & 0.15 & 0.16 & 0.16 & 0.16 & 0.16 & 0.16 \\
\hline Iran & 2.02 & 2.00 & 1.95 & 1.94 & 1.94 & 1.95 & 1.94 & 1.92 & 1.91 \\
\hline Iraq & 4.56 & 3.63 & 3.80 & 3.80 & 3.94 & 4.02 & 4.14 & 4.14 & 4.14 \\
\hline Kuwait & 2.71 & 2.29 & 2.30 & 2.30 & 2.38 & 2.42 & 2.47 & 2.50 & 2.50 \\
\hline Libya & 0.35 & 0.63 & 0.64 & 0.68 & 0.73 & 0.79 & 0.80 & 0.80 & 0.79 \\
\hline Nigeria & 1.73 & 1.50 & 1.50 & 1.50 & 1.55 & 1.58 & 1.58 & 1.58 & 1.58 \\
\hline Saudi Arabia & 9.77 & 9.14 & 8.99 & 8.99 & 9.49 & 9.49 & 9.49 & 9.68 & 9.78 \\
\hline UAE & 3.20 & 2.69 & 2.59 & 2.59 & 2.65 & 2.69 & 2.76 & 2.79 & 2.82 \\
\hline Venezuela & 0.77 & 0.59 & 0.57 & 0.59 & 0.64 & 0.71 & 0.78 & 0.88 & 0.99 \\
\hline Oil field production & 28.65 & 25.48 & 25.48 & 25.53 & 26.54 & 26.85 & 27.16 & 27.48 & 27.66 \\
\hline Other production & 4.54 & 4.71 & 4.72 & 4.74 & 4.78 & 4.81 & 4.82 & 4.82 & 4.82 \\
\hline \multirow[t]{2}{*}{ OPEC } & 33.18 & 30.19 & 30.20 & 30.28 & 31.32 & 31.66 & 31.98 & 32.30 & 32.48 \\
\hline & Q1 2020 & Q2 2020 & Q3 2020 & Q4 2020 & Q1 2021 & Q2 2021 & Q3 2021 & Q4 2021 & Q4 2022 \\
\hline Call on OPEC & 33.10 & 30.83 & 25.78 & 33.81 & 34.94 & 35.02 & 36.56 & 36.33 & 35.59 \\
\hline OPEC & 33.18 & 30.19 & 30.20 & 30.28 & 31.32 & 31.66 & 31.98 & 32.30 & 32.48 \\
\hline Non-OPEC & 66.84 & 62.45 & 59.87 & 59.80 & 62.43 & 62.61 & 62.46 & 62.82 & 62.71 \\
\hline Total & 100.02 & 92.64 & 90.07 & 90.07 & 93.75 & 94.28 & 94.44 & 95.11 & 95.18 \\
\hline
\end{tabular}




\section{Glossary}

MMb/d One million barrels of oil per day

$\mathbf{K b} / \mathbf{d} \quad$ One thousand barrels of oil per day

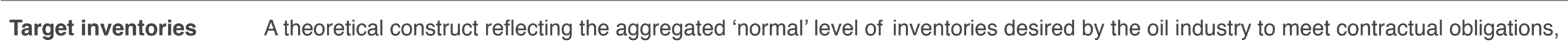
provide a cushion for the complex supply chain that tends to deliver the product in 'batches,' and buffer unanticipated changes in the supply of and demand for crude oil. It is derived from OECD inventory data using a trend component reflecting long-term economic growth, and a seasonal component reflecting phenomena such as the winter heating season, and summer driving and cooling seasons.

\begin{tabular}{|c|c|}
\hline Real inventories & Represents the real inventory levels based on KOMO's forecast of supply/demand and inventory surplus/deficit balances. \\
\hline Hedging pressure & $\mathrm{HP}=\mathrm{PMnS}-\mathrm{MMnL}$, where PMnS is producer/merchant/processor/user net short, and MMnL is managed money net long. \\
\hline SW & Swap dealers \\
\hline MM & Managed money \\
\hline OR & Other reporters \\
\hline NR & Non-reporters \\
\hline OPEC partners & Azerbaijan, Bahrain, Brunei, Kazakhstan, Malaysia, Mexico, Oman, Russia, South Sudan and Sudan \\
\hline
\end{tabular}




\section{About KAPSARC}

The King Abdullah Petroleum Studies and Research Center (KAPSARC) is a non-profit global institution dedicated to independent research into energy economics, policy, technology and the environment across all types of energy. KAPSARC's mandate is to advance the understanding of energy challenges and opportunities facing the world today and tomorrow, through unbiased, independent, and high-caliber research for the benefit of society. KAPSARC is located in Riyadh, Saudi Arabia.
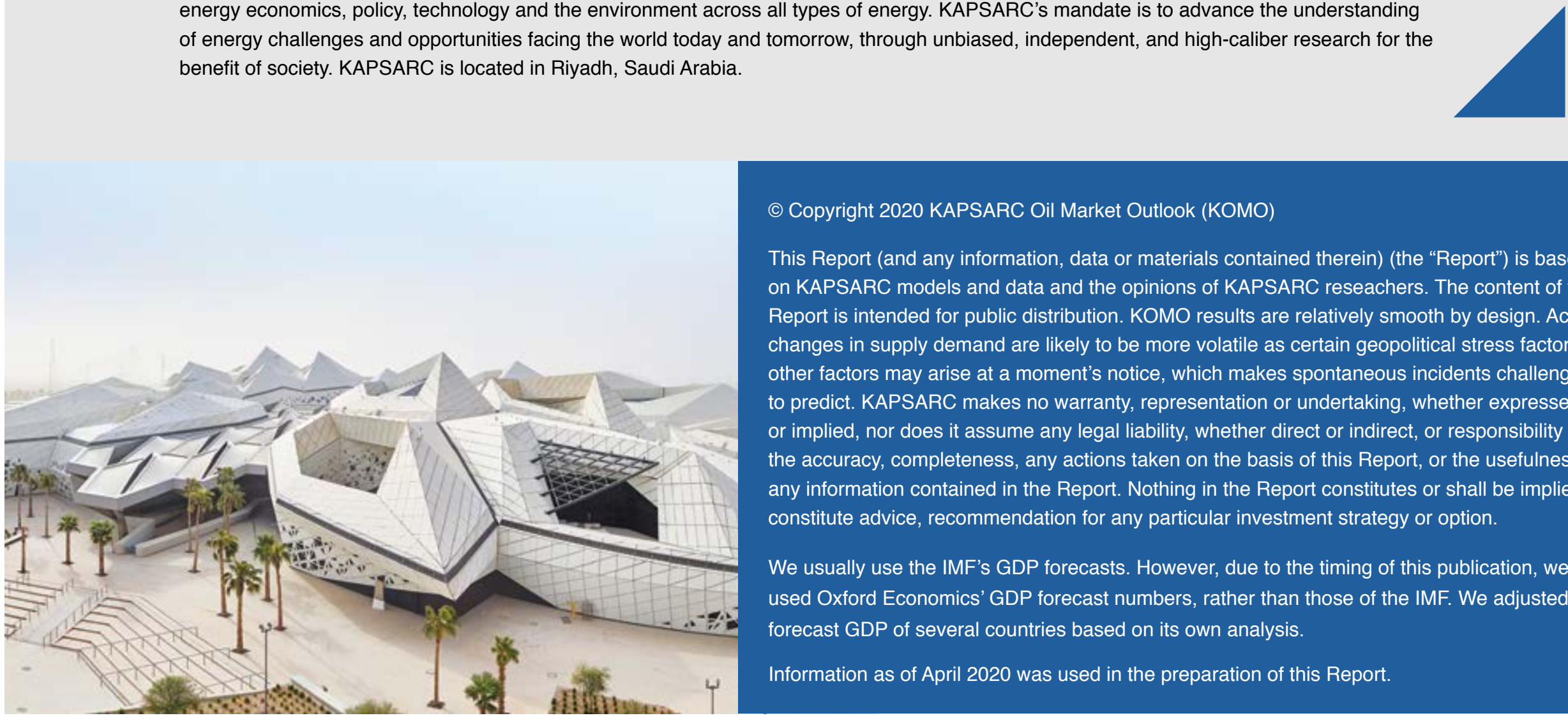

(c) Copyright 2020 KAPSARC Oil Market Outlook (KOMO)

This Report (and any information, data or materials contained therein) (the "Report") is based on KAPSARC models and data and the opinions of KAPSARC reseachers. The content of this Report is intended for public distribution. KOMO results are relatively smooth by design. Actual changes in supply demand are likely to be more volatile as certain geopolitical stress factors and other factors may arise at a moment's notice, which makes spontaneous incidents challenging to predict. KAPSARC makes no warranty, representation or undertaking, whether expressed or implied, nor does it assume any legal liability, whether direct or indirect, or responsibility for the accuracy, completeness, any actions taken on the basis of this Report, or the usefulness of any information contained in the Report. Nothing in the Report constitutes or shall be implied to constitute advice, recommendation for any particular investment strategy or option.

We usually use the IMF's GDP forecasts. However, due to the timing of this publication, we used Oxford Economics' GDP forecast numbers, rather than those of the IMF. We adjusted the forecast GDP of several countries based on its own analysis.

Information as of April 2020 was used in the preparation of this Report. 


\section{KaPSARC}

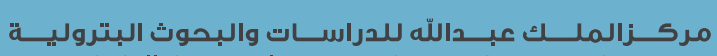
King Abdullah Petroleum Studies and Research Center

www.kapsarc.org 